Paper published in:

D. Gallipoli, A.W. Bruno, F. D’Onza, C. Mancuso (2015).

A bounding surface hysteretic water retention model for deformable soils.

Géotechnique, 65(10): 793-804

http://www.icevirtuallibrary.com/doi/full/10.1680/jgeot.14.P.118

\title{
A BOUNDING SURFACE HYSTERETIC WATER RETENTION MODEL FOR DEFORMABLE SOILS
}

Domenico Gallipoli', Agostino Walter Bruno², Francesca D'Onza ${ }^{3}$, Claudio Mancuso ${ }^{4}$

1 Professor, Laboratoire SIAME, Université de Pau et des Pays de l'Adour, Anglet, France, email: domenico.gallipoli@univ-pau.fr

2 PhD student, Laboratoire SIAME, Université de Pau et des Pays de l'Adour, Anglet, France, email: agostinowalter.bruno@univ-pau.fr

3 Researcher, ENEA, Italian National Agency for new technologies, energy and sustainable economic development, Portici, Italy, email: francesca.donza@enea.it

4 Professor, Dipartimento di Ingegneria Civile, Edile e Ambientale, Università di Napoli Federico II, Napoli, Italy, email: mancuso@unina.it

DATE OF SUBMISSION: 2/5/2015

NUMBER OF WORDS: 5846

NUMBER OF TABLES: 2

NUMBER OF FIGURES: 12

CORRESPONDING AUTHOR: Prof Domenico Gallipoli

Université de Pau et des Pays de l'Adour

Laboratoire SIAME - Bâtiment ISABTP

Allée du Parc Montaury

64600 Anglet

France

e-mail: domenico.gallipoli@univ-pau.fr 
ABSTRACT: The paper presents a soil water retention model that takes into account the effects of void ratio and hydraulic hysteresis on the variation of degree of saturation. Based on a modified form of van Genuchten equation, the model defines two bounding surfaces, i.e. a main drying surface and a main wetting surface, which delimit the region of admissible soil states in the space of degree of saturation, suction and void ratio. Suction and void ratio are then combined into a single auxiliary variable, named scaled suction, and the main surfaces are recast as main curves in the plane of degree of saturation and scaled suction. The effects of both suction and void ratio on the drying/wetting behaviour of the soil are simply incorporated by relating degree of saturation to scaled suction. The soil is dried when the scaled suction is increased and is wetted when the scaled suction is decreased. The model assumes that, inside the region of admissible soil states, the derivative of degree of saturation with respect to the scaled suction depends on the distance of the soil state from the main curves. This assumption ensures a smooth transition of the drying and wetting paths towards their respective main curves. Interestingly, the derivative of degree of saturation with respect to scaled suction can be integrated in a closed form and all wetting and drying paths can therefore be described by two explicit equations (one for drying paths and one for wetting paths), where different wetting or drying paths are characterized by different values of the integration constant. The integration of the model in a closed form facilitates its implementation into numerical codes. The model requires seven parameters, whose values can be obtained from a single drying-wetting test. Predictions are validated against two different data sets published in the literature, which shows the capability of the model to capture the behaviour observed during laboratory tests on fine grained soils.

KEYWORDS: soil water retention, soil water characteristic curve, unsaturated soils, partial saturation, suction, constitutive relations, bounding surface 


\section{INTRODUCTION}

Understanding water retention in soils is essential for many applications in agriculture and engineering, from irrigation to groundwater pumping, from the design of superficial foundations to the study underground gas/liquid flow. A number of authors have proposed a variety of soil water retention laws, ranging from simple curves relating the degree of saturation to suction (e.g. Brooks \& Corey, 1964; Van Genuchten, 1980; Fredlund \& Xing, 1994), to more complex models where water retention is influenced by soil deformation through the dependency of degree of saturation on void ratio (e.g. Gallipoli et al., 2003; Sun et al., 2008; Mašín, 2010; Salager et al., 2010). In a limited number of models, the effect of deformation on water retention has been introduced by taking into account the change of the entire pore size distribution rather than void ratio alone (e.g. Hu et al., 2013; Russell, 2014). Finally, other authors have improved the description of soil water retention by incorporating the influence of hydraulic hysteresis (e.g. Wheeler et al., 2003; Li, 2005; Khalili et al., 2008; Nuth \& Laloui, 2008; Tarantino, 2009; Pedroso \& Williams, 2010; Gallipoli, 2012; Zhou et al., 2012; Tsiampousi et al., 2013).

This paper presents a water retention model that takes into account the effects of both soil deformation and hydraulic hysteresis on the variation of degree of saturation with suction. Similar to Gallipoli (2012), the model is based on the definition of two bounding surfaces, i.e. a "main drying surface" and a "main wetting surface", which delimit the region of admissible soil states in the space of degree of saturation, suction and void ratio. However, unlike Gallipoli (2012), the model combines void ratio and suction into a single variable, named "scaled suction", so that the main surfaces can be recast as main curves delimiting the region of admissible soil states in the plane of degree of saturation and scaled suction. Inside this region, the derivative of degree of saturation with respect to scaled suction is assumed to depend on the distance of the current soil state from the main curves, which ensures a smooth transition of all drying and wetting paths towards their respective main curves. An important advantage is that the derivative of degree of saturation with respect to scaled suction can be integrated in a closed form, so that all wetting 
and drying paths can be described by two explicit equations (one for drying paths and one for wetting paths), with distinct wetting or drying paths characterized by different values of the integration constant. The description of the hysteretic water retention behaviour of the soil by means of closed form equations facilitates the implementation of the model into numerical codes. The model requires seven parameters, all with clear physical meanings, whose values can be obtained from a single drying-wetting test. In the second part of the paper, the model is calibrated and validated on the basis of two different laboratory data sets published in the literature, showing a good capability to capture the behaviour of fine grained soils.

\section{FORMULATION OF MAIN SURFACES}

The water retention equation of van Genuchten (1980) has been widely used to describe the relationship between degree of saturation $S_{r}$ and suction $s$ in soils:

$$
S_{r}=\left(1+(s \alpha)^{\mathrm{n}}\right)^{-\mathrm{m}}
$$

where $\alpha, \mathrm{m}$ and $\mathrm{n}$ are soil parameters.

Gallipoli et al. (2003) presented a modified form of equation (1) that takes into account the dependency of degree of saturation not only on suction but also on deformation. This was achieved by expressing the parameter $\alpha$ of equation (1) as a power function of void ratio $e$ :

$$
\alpha=\phi e^{\psi}
$$

where $\phi$ and $\psi$ are soil parameters. To simplify the geometrical interpretation of model parameters in the following part of the paper, we here replace the parameter $\phi$ with its reciprocal $\omega=\frac{1}{\phi}$ so that equation (2a) is rewritten as: 


$$
\alpha=\frac{e^{\psi}}{\omega}
$$

While the retention equation of van Genuchten (1980) describes a curve in the $S_{r}-s$ plane, the retention equation of Gallipoli et al. (2003) describes a surface in the $S_{r}-s-e$ space as:

$$
S_{r}=\left(1+\left(s \frac{e^{\psi}}{\omega}\right)^{\mathrm{n}}\right)^{-\mathrm{m}}
$$

Accordingly, the number of parameters increases from three $(m, n$ and $\alpha)$, in the model of van Genuchten (1980), to four ( $\mathrm{m}, \mathrm{n}, \omega$ and $\psi$ ), in the model of Gallipoli et al. (2003).

Gallipoli (2012) extended the model of Gallipoli et al. (2003) by incorporating hydraulic hysteresis via the definition of two main retention surfaces, i.e. a main drying surface and a main wetting surface, which delimit the region of attainable soil states in the $S_{r}-s-e$ space and are both described by equations (3) but with different parameter values:

$$
S_{r}=\left(1+\left(s \frac{e^{\psi_{\mathrm{i}}}}{\omega_{\mathrm{i}}}\right)^{\mathrm{n}_{\mathrm{i}}}\right)^{-\mathrm{m}_{\mathrm{i}}}
$$

In equations (4a), the parameter subscript " $i$ " is equal to either " $d$ " or " $w$ " depending on whether the equation refers to a main drying or a main wetting surface. A total of eight parameters are therefore needed to describe the main hysteretic behaviour: four parameters for the main drying surface $\left(m_{d}, n_{d}, \omega_{d}\right.$ and $\left.\psi_{\mathrm{d}}\right)$ and four parameters for the main wetting surface $\left(\mathrm{m}_{\mathrm{w}}, \mathrm{n}_{\mathrm{w}}, \omega_{\mathrm{w}}\right.$ and $\left.\psi_{\mathrm{w}}\right)$.

As shown by Gallipoli (2012), the retention surface of equation (4a) can be recast in the $\log S_{r}-\log s-$ $\log e$ space as: 


$$
\log S_{r}=-\mathrm{m}_{\mathrm{i}} \mathrm{n}_{\mathrm{i}}\left(\log s-\log \omega_{\mathrm{i}}\right)-\mathrm{m}_{\mathrm{i}} \mathrm{n}_{\mathrm{i}} \psi_{\mathrm{i}} \log e-\mathrm{m}_{\mathrm{i}} \log \left(1+\left(\frac{\omega_{\mathrm{i}}}{s e^{\psi_{\mathrm{i}}}}\right)^{\mathrm{n}_{\mathrm{i}}}\right)
$$

The cross sections of the main drying and wetting surfaces at constant $e$, are named "main isochoric desiccation curves" and "main isochoric soaking curves", respectively. Similarly, the cross sections of the main drying and wetting surfaces at constant $s$, are named "main isosuction swelling curves" and "main isosuction compression curves", respectively.

Inspection of equation (4b) indicates that:

1. in a $\log S_{r}-\log s$ plane at constant $e$, the main isochoric desiccation and soaking curves tend, as $s$ grows large, towards their respective linear asymptotes with slopes $\lambda_{s \mathrm{i}}=\mathrm{m}_{\mathrm{i}} \mathrm{n}_{\mathrm{i}}$ (see Fig. 1);

2. in a $\log S_{r}-\log e$ plane at constant $s$, the main isosuction swelling and compression curves tend, as $e$ grows large, towards their respective linear asymptotes with slopes $\lambda_{e \mathrm{i}}=\mathrm{m}_{\mathrm{i}} \mathrm{n}_{\mathrm{i}} \psi_{\mathrm{i}}$ (see Fig. 2);

3. in the $\log S_{r}-\log s$ plane at constant $e=1$, the intercepts of the linear asymptotes of the main isochoric desiccation and soaking curves with the $\log S_{r}=0$ axis are equal to $\log \omega_{\mathrm{i}}$ (see Fig. 3);

4. by recalling equation (4a), the last term of equation (4b), i.e. $m_{i} \log \left(1+\left(\frac{\omega_{i}}{s e^{\psi_{i}}}\right)^{n_{i}}\right)$, can be rewritten as $\mathrm{m}_{\mathrm{i}} \log \left(1+\frac{1}{s_{r}-\frac{1}{\mathrm{~m}_{\mathrm{i}}}-1}\right)$, where only the degree of saturation and the parameter $\mathrm{m}_{\mathrm{i}}$ appear.

Based on the above observations, the main retention surfaces of equations (4a) and (4b) are rewritten below in terms of parameters $m_{i}, \omega_{i}, \lambda_{s i}$ and $\lambda_{e i}$, instead of parameters $m_{i}, n_{i}, \omega_{i}$ and $\psi_{i}$. This is preferable 
given the clearer geometrical/physical interpretation of the former set of parameters compared to the latter one.

$$
\begin{aligned}
& S_{r}=\left(1+\left(s \frac{e^{\frac{\lambda_{e \mathrm{i}}}{\lambda_{s i}}}}{\omega_{\mathrm{i}}}\right)^{\frac{\lambda_{s \mathrm{i}}}{\mathrm{m}_{\mathrm{i}}}}\right)^{-\mathrm{m}_{\mathrm{i}}} \\
& \log S_{r}=-\lambda_{s \mathrm{i}}\left(\log s-\log \omega_{\mathrm{i}}\right)-\lambda_{e \mathrm{i}} \log e-\mathrm{m}_{\mathrm{i}} \log \left(1+\frac{1}{S_{r}^{-\frac{1}{\mathrm{~m}_{\mathrm{i}}}}-1}\right)
\end{aligned}
$$

As before, in equations (5a) and (5b), the subscript " $\mathrm{i}$ " is equal to " $\mathrm{d}$ " for the main drying surface and to " $w$ " for the main wetting surface.

\section{PARAMETERS FOR THE MAIN RETENTION SURFACES}

In this section, we show that, based on experimental evidence, the number of parameters governing the main hysteretic behaviour can be reduced from eight to six and a number of restrictions can also be placed on the range of parameter values.

Several authors (Salager et al., 2013; Casini et al., 2012; Romero et al., 2011; Tarantino, 2009) have observed that the main isochoric desiccation and soaking curves, when expressed in terms of water ratio $e_{w}=S_{r} e$ (or, equivalently, in terms of water content $w=\frac{S_{r} e}{\mathrm{G}_{\mathrm{s}}}$ ) instead of degree of saturation, become independent of void ratio at high suction levels (see Fig. 4). In other words, the curves relating $e_{w}$ and $s$ at a constant $e$ tend to merge into a unique relationship when suction becomes large (see Fig. 4). This is because the soil attains a given void ratio through the deformation of its larger pores, which are drained/filled at low suctions, while the smaller pores, which are drained/filled at high suctions, tend to 
remain undeformed. Therefore, two different suction (or pore) ranges can be identified for each main isochoric desiccation or soaking curve:

a) A low suction range corresponding to the drainage/flooding of the larger "deformed" pores. Given that these pores have previously experienced some degree of deformation, this part of the curve depends on the current value of void ratio.

b) A high suction range corresponding to the drainage/flooding of the smaller "virgin" pores. Given that these pores have not yet experienced any deformation, this part of the curve is independent of the current value of void ratio.

The upper limit of the low suction range corresponds to the size of the smallest deformed pore, while the lower limit of the high suction range corresponds to the size of the largest virgin (i.e. undeformed) pore. By assuming a continuous pore size distribution, these two pore sizes coincide, which means that the upper limit of the low suction range and the lower limit of the high suction range also coincide at a "transition" value of suction. This value of suction, which marks the transition from drainage/flooding of the (larger) deformed pores to drainage/flooding of the (smaller) virgin pores, becomes bigger as the void ratio decreases due to the fact that increasingly smaller pores are being affected by deformation. Because of this, distinct isochoric desiccation or soaking curves at a different value of void ratio should have a different value of transition suction.

As demonstrated by Gallipoli (2012), if parameter $\lambda_{e \mathrm{i}}$ is set equal to one in equation (5), the predicted relationship between $e_{w}$ and $s$ becomes independent of void ratio at high suction levels, which is in agreement with the above experimental evidence. Fig. 5 shows typical $e_{w}$ versus $s$ isochoric desiccation and soaking curves predicted by equation (5) with $\lambda_{e \mathrm{i}}=1$ for different values of void ratio. When suction grows large, these isochoric desiccation and soaking curves tend towards the drying and wetting 
asymptotes (here referred to as "virgin drying line" and "virgin wetting line" because they describe the drying/flooding of the virgin, undeformed pores). Consistent with experimental evidence, the predicted relationship between $e_{w}$ and $s$ in Fig. 5 becomes independent of void ratio at high suction levels and also shows increasing values of transition suction as the void ratio decreases.

After setting $\lambda_{e \mathrm{i}}$ equal to one for both drying and wetting surfaces, the number of independent parameters governing the main retention behaviour of the soil reduces from eight to six (namely three parameters for the main drying surface $m_{d}, \omega_{d}, \lambda_{s d}$ and three parameters for the main wetting surface $m_{w}, \omega_{w}, \lambda_{s w}$ ) and equations (5a) and ( $5 b)$ are therefore rewritten as:

$$
\begin{gathered}
S_{r}=\left(1+\left(s \frac{e^{\frac{1}{\lambda_{s \mathrm{i}}}}}{\omega_{\mathrm{i}}}\right)^{\frac{\lambda_{s \mathrm{i}}}{\mathrm{m}_{\mathrm{i}}}}\right)^{-\mathrm{m}_{\mathrm{i}}} \\
\log S_{r}=-\lambda_{s \mathrm{i}}\left(\log s-\log \omega_{\mathrm{i}}\right)-\log e-\mathrm{m}_{\mathrm{i}} \log \left(1+\frac{1}{S_{r}-\frac{1}{\mathrm{~m}_{\mathrm{i}}}-1}\right)
\end{gathered}
$$

Note that, when $s \rightarrow \infty$ or $e \rightarrow \infty$ (i.e. when $S_{r} \rightarrow 0$ ), the last term of equation (6b) vanishes and the main retention surface tends towards a planar asymptote, $\log \overrightarrow{S_{r}}$ :

$$
\log \overrightarrow{S_{r}}=-\lambda_{s i}\left(\log s-\log \omega_{\mathrm{i}}\right)-\log e
$$

The deviation, $\Delta \log S_{r}$ of the main retention surface from this planar asymptote is therefore:

$$
\Delta \log S_{r}=\log S_{r}-\log \overrightarrow{S_{r}}=-\mathrm{m}_{\mathrm{i}} \log \left(1+\frac{1}{S_{r}-\frac{1}{\mathrm{~m}_{\mathrm{i}}}-1}\right)
$$


Inspection of equations (7) and (8) indicates that, while the two parameters $\omega_{\mathrm{i}}$ and $\lambda_{s i}$ control the intercept and slope of the log-linear asymptotes of the isochoric desiccation and soaking curves, the parameter $\mathrm{m}_{\mathrm{i}}$ describes the progressive deviation of these two curves from their respective asymptotes as degree of saturation increases (see Fig.6).

The values of the above six parameters must also satisfy the following restrictions:

- $\lambda_{s \mathrm{~d}}>0$ and $\lambda_{s \mathrm{w}}>0$

Positiveness of $\lambda_{s i}$ is necessary to ensure that the degree of saturation decreases monotonically with increasing suction (see equation (5) in Gallipoli, 2012);

- $\omega_{\mathrm{d}}>0$ and $\omega_{\mathrm{w}}>0$

Positiveness of $\omega_{\mathrm{i}}$ is necessary to ensure that the term $s \frac{e^{\frac{1}{\lambda_{s i}}}}{\omega_{\mathrm{i}}}$ in equation $(6 \mathrm{a})$ is also positive (recall that $s$ and $e$ are both positive). This term has to be positive because it is the argument of a fractional power with exponent $\frac{\lambda_{s i}}{\mathrm{~m}_{\mathrm{i}}}$;

- $\mathrm{m}_{\mathrm{d}}>0$ and $\mathrm{m}_{\mathrm{w}}>0$

Positiveness of $\mathrm{m}_{\mathrm{i}}$ is necessary to ensure that the calculated value of degree of saturation $S_{r}$ is always comprised between zero and one. This is because the term $1+\left(s \frac{e^{\frac{1}{\lambda_{s i}}}}{\omega_{\mathrm{i}}}\right)^{\frac{\lambda_{s \mathrm{i}}}{\mathrm{m}_{\mathrm{i}}}}$ in equation (6a) ranges between one and infinity and is the argument of a power with exponent $-m_{i}$. This 
exponent must always be negative ( $m_{i}$ must, hence, be always positive) in order for the degree of saturation to be bound between zero and one.

- $\frac{\mathrm{m}_{\mathrm{w}}}{\mathrm{m}_{\mathrm{d}}} \geq \frac{\lambda_{s \mathrm{w}}}{\lambda_{s \mathrm{~d}}} \geq 1$

This restriction is introduced because, for any pair of $S_{r}$ and $e$, the suction on the main drying surface must always be greater than the suction on the main wetting surface. In particular, this must be true when $S_{r} \rightarrow 0$ and when $S_{r} \rightarrow 1$, which leads to the restriction on parameter values of equation (12a) (see Appendix A for a proof). If any of the two relationships in equation (12a) is verified with the equal sign, the following additional restriction must be verified over the relevant range of $e$ (see Appendix A for a proof):

- $\frac{\omega_{\mathrm{w}}}{\omega_{\mathrm{d}}} \leq\left(\frac{\lambda_{s \mathrm{w}}}{\lambda_{s \mathrm{~d}}}\right)^{\frac{\mathrm{m}_{\mathrm{w}}}{\lambda_{s \mathrm{w}}}} e^{-\frac{\lambda_{s \mathrm{w}}-\lambda_{S \mathrm{~d}}}{\lambda_{s \mathrm{w}} \lambda_{s \mathrm{~d}}}}$

BOUNDING SURFACE RETENTION MODEL

This section presents a bounding surface retention model capable of predicting the variation of degree of saturation along generic wetting and drying paths over the region of admissible soil states delimited by the two main retention surfaces.

We first introduce the auxiliary variable $\bar{s}=s e^{\frac{1}{\lambda_{s i}}}$, which we name scaled suction (see also Tarantino, 2009). By using the scaled suction $\bar{s}$, we recast the three-dimensional main drying and main wetting surfaces of equation (6a) into two-dimensional main drying and wetting "scaled curves" in the $S_{r}-\bar{s}$ plane: 


$$
S_{r}=\left(1+\left(\frac{\bar{S}}{\omega_{\mathrm{i}}}\right)^{\frac{\lambda_{\mathrm{si}}}{\mathrm{m}_{\mathrm{i}}}}\right)^{-\mathrm{m}_{\mathrm{i}}}
$$

Drying paths are then simply defined as paths where the value of the scaled suction $\bar{s}$ increases, while wetting paths are defined as paths where the value of the scaled suction $\bar{s}$ decreases. Another important consequence of formulating the model in terms of scaled suction is that the two parameters $\lambda_{s \mathrm{~d}}$ and $\lambda_{s \mathrm{w}}$ must now be identical in order to ensure the continuity of the stress path at the reversal point of a dryingwetting cycle in the $S_{r}-\bar{s}$ plane. In fact, if the two parameters $\lambda_{s \mathrm{~d}}$ and $\lambda_{s \mathrm{w}}$ are not identical, the value of scaled suction $\bar{s}$ corresponding to a given pair of $e$ and $s$ is no longer unique but depends on whether the soil is assumed to be on a drying path, in which case $\bar{s}=s e^{\frac{1}{\lambda_{s d}}}$, or on a wetting path, in which case $\bar{s}=s e^{\frac{1}{\lambda_{s \mathrm{w}}}}$. In order to avoid this problem, we pose $\lambda_{s \mathrm{~d}}=\lambda_{s \mathrm{w}}=\lambda_{s}$. A consequence of this is that the parameter restrictions of equations (9) to (12) can now be rewritten in a simpler form as:

- $\lambda_{s}>0$

- $\mathrm{m}_{\mathrm{w}} \geq \mathrm{m}_{\mathrm{d}}>0$

$$
\text { - } \quad \omega_{\mathrm{d}} \geq \omega_{\mathrm{w}}>0
$$

The derivatives of the main scaled curves are obtained by differentiating equation (13):

$$
\frac{d S_{r}}{d \bar{s}}=-\frac{\lambda_{s}}{\bar{s}} S_{r}^{1+\frac{1}{\mathrm{~m}_{\mathrm{i}}}}\left(S_{r}^{-\frac{1}{\mathrm{~m}_{\mathrm{i}}}}-1\right)
$$

while the value of scaled suction $\bar{s}_{\mathrm{i}}$ corresponding to a given value of $S_{r}$ on the main scaled curves is obtained by inverting equation (13) as: 


$$
\bar{s}_{\mathrm{i}}=\omega_{\mathrm{i}}\left(S_{r}^{-\frac{1}{\mathrm{~m}_{\mathrm{i}}}}-1\right)^{\frac{\mathrm{m}_{\mathrm{i}}}{\lambda_{s}}}
$$

As before, the subscript " $\mathrm{i}$ " in equations (13)-(18) is equal to either " $\mathrm{d}$ " or " $w$ " depending on whether a main drying or a main wetting scaled curve is being considered.

\section{Drying surfaces}

Following Zhou et al. (2012), we assume that inside the region of admissible soil states in the $S_{r}-\bar{s}$ plane, the derivative $\left(\frac{d S_{r}}{d \bar{s}}\right)_{\mathrm{d}}$ of a generic drying scaled curve is proportional to the derivative $\left(\frac{\mathrm{d} S_{\mathrm{r}}}{\mathrm{d} \bar{s}_{\mathrm{d}}}\right)_{\mathrm{Md}}$ of the main drying scaled curve at the same value of $S_{r}$ as:

$$
\left(\frac{\mathrm{d} S_{\mathrm{r}}}{\mathrm{d} \log \bar{s}}\right)_{\mathrm{d}}=\left(\frac{\bar{s}}{\bar{s}_{\mathrm{d}}}\right)^{\beta_{\mathrm{d}}}\left(\frac{\mathrm{d} S_{\mathrm{r}}}{\mathrm{d} \log \bar{s}_{\mathrm{d}}}\right)_{\mathrm{Md}} \Rightarrow\left(\frac{\mathrm{d} S_{\mathrm{r}}}{\mathrm{d} \bar{s}}\right)_{\mathrm{d}}=\frac{\bar{s}^{\beta_{\mathrm{d}}-1}}{\bar{s}_{\mathrm{d}} \beta_{\mathrm{d}}-1}\left(\frac{\mathrm{d} S_{\mathrm{r}}}{\mathrm{d} \bar{s}_{\mathrm{d}}}\right)_{\mathrm{Md}}
$$

Inspection of equation (19) indicates that the proportionality factor between the two derivatives is a power function (with exponent $\beta_{\mathrm{d}}$ ) of the ratio between the current value of scaled suction, $\bar{s}$, and the "image" value of scaled suction, $\bar{s}_{\mathrm{d}}$. The image value of scaled suction is the value of scaled suction on the main

drying scaled curve corresponding to the current value of $S_{r}$ and is given by equation (18). The ratio $\frac{\bar{s}}{\bar{s}_{\mathrm{d}}}$ is therefore always smaller than one and tends towards one as suction increases and the drying path approaches the main drying scaled curve. So, according to equation (19), the slope of a generic drying scaled curve increases progressively towards the slope of the main drying scaled curve as the scaled suction increases. This, in turn, means that a generic drying scaled curve tends asymptotically towards the main drying scaled curve as scaled suction grows large. 
In equation (19) we substitute equation (17) for $\left(\frac{\mathrm{d} s_{\mathrm{r}}}{\mathrm{d} \bar{s}_{\mathrm{d}}}\right)_{M d}$ and equation (18) for $\bar{s}_{\mathrm{d}}$, which yields the following expression for the derivative of a generic drying scaled curve:

$$
\left(\frac{d S_{r}}{d \bar{s}}\right)_{\mathrm{d}}=-\frac{\lambda_{s}}{\omega_{\mathrm{d}}^{\beta}} \bar{s}^{\beta_{\mathrm{d}}-1} S_{r}^{1+\frac{1}{\mathrm{~m}_{\mathrm{d}}}}\left(S_{r}^{-\frac{1}{\mathrm{~m}_{\mathrm{d}}}}-1\right)^{1-\frac{\beta_{\mathrm{d}} \mathrm{m}_{\mathrm{d}}}{\lambda_{s}}}
$$

Very interestingly, equation (20) can be integrated in a closed form to give:

$$
\left(S_{r}\right)_{\mathrm{d}}=\left(1+\left(\frac{\bar{s}^{\beta_{\mathrm{d}}}+\mathrm{C}_{\mathrm{d}}}{\omega_{\mathrm{d}}^{\beta_{\mathrm{d}}}}\right)^{\frac{\lambda_{s}}{\beta_{\mathrm{d}} \mathrm{m}_{\mathrm{d}}}}\right)^{-\mathrm{m}_{\mathrm{d}}}
$$

where $C_{d}$ is a constant of integration greater than or equal to zero (see Appendix $B$ ), which must be calculated by imposing a suitable boundary condition, i.e. by imposing that the drying scaled curve of equation (21) passes through a known soil state in the $S_{r}-\bar{s}$ plane. For example, the value of $\mathrm{C}_{\mathrm{d}}$ can be calculated to match the initial soil state by substituting the initial values of degree of saturation and scaled suction in equation (21) (or, equivalently, in equation (B1) of Appendix B), where the initial value of scaled suction is, of course, obtained from the initial values of suction and void ratio, i.e. $\bar{s}=s e^{\frac{1}{\lambda_{s}}}$.

By substituting the definition of scaled suction $\bar{s}=s e^{\frac{1}{\lambda_{s}}}$ inside equation (21), we obtain the following expression for the generic drying surface in the $S_{r}-s-e$ space:

$$
\left(S_{r}\right)_{\mathrm{d}}=\left(1+\left(\frac{\left(s e^{\left.\frac{1}{\lambda_{s}}\right)^{\beta_{\mathrm{d}}}}+C_{\mathrm{d}}\right.}{\omega_{\mathrm{d}}^{\beta_{\mathrm{d}}}}\right)^{\frac{\lambda_{s}}{\beta_{\mathrm{d}} \mathrm{m}_{\mathrm{d}}}}\right)^{-\mathrm{m}_{\mathrm{d}}}
$$


Equation (22) describes all drying paths inside the region delimited by the two main surfaces, including the drying paths that take place on the main drying surface itself (indeed, equation (22) reduces to the main drying surface of equation (6a) when $C_{d}$ is equal to zero). A single equation is therefore needed to describe all drying paths, each path being identified by a different value of the constant $C_{d}$.

\section{Wetting surfaces}

As for the drying case, we assume that the derivative $\left(\frac{d S_{r}}{d \bar{s}}\right)_{\mathrm{w}}$ of a generic wetting scaled curve inside the region of admissible soil states is proportional to the derivative $\left(\frac{\mathrm{d} S_{\mathrm{r}}}{\mathrm{d} \bar{s}_{\mathrm{w}}}\right)_{\mathrm{Mw}}$ of the main wetting scaled curve at the same value of $S_{r}$ :

$$
\left(\frac{\mathrm{d} S_{\mathrm{r}}}{\mathrm{d} \log \bar{s}}\right)_{\mathrm{w}}=\left(\frac{\bar{s}_{\mathrm{W}}}{\bar{s}}\right)^{\beta_{\mathrm{w}}}\left(\frac{\mathrm{d} S_{\mathrm{r}}}{\mathrm{d} \log \bar{s}_{\mathrm{w}}}\right)_{\mathrm{Mw}} \Rightarrow\left(\frac{\mathrm{d} S_{\mathrm{r}}}{\mathrm{d} \bar{s}}\right)_{\mathrm{w}}=\frac{\bar{s}_{\mathrm{W}} \beta_{\mathrm{w}}+1}{\bar{s}^{\beta_{\mathrm{w}}}+1}\left(\frac{\mathrm{d} S_{\mathrm{r}}}{\mathrm{d} \bar{s}_{\mathrm{w}}}\right)_{\mathrm{MW}}
$$

In this case, the proportionality factor linking the two derivatives in equation (23) is a power function of the ratio between the image value of scaled suction $\bar{s}_{\mathrm{w}}$ and the current value of scaled suction $\bar{s}$ (instead of being the ratio between the current value of scaled suction and the image value of scaled suction as in the drying case). The image value $\bar{s}_{\mathrm{W}}$ is calculated on the main wetting scaled curve in correspondence of the current value of $S_{r}$ and is given by equation (18). According to equation (23), when the scaled suction decreases and the soil state approaches the main wetting scaled curve, the slope of the wetting path increases towards the slope of the main wetting scaled curve. This means that, as in the drying case, the soil path tends asymptotically towards the main wetting scaled curve when scaled suction is reduced.

By substituting equations (17) and (18) into equation (23), we obtain the following expression for the derivative of the generic wetting scaled curve: 


$$
\left(\frac{d S_{r}}{d \bar{s}}\right)_{\mathrm{w}}=-\frac{\lambda_{s} \omega_{\mathrm{w}}^{\beta_{\mathrm{w}}}}{\bar{s}_{\mathrm{w}}+1} S_{r}^{1+\frac{1}{\mathrm{~m}_{\mathrm{w}}}}\left(S_{r}^{-\frac{1}{\mathrm{~m}_{\mathrm{w}}}}-1\right)^{1+\frac{\beta_{\mathrm{w}} \mathrm{m}_{\mathrm{w}}}{\lambda_{s}}}
$$

Remarkably, equation (24) can also be integrated in a closed form to give:

$$
\left(S_{r}\right)_{\mathrm{w}}=\left(1+\left(\frac{\bar{s}^{\beta_{\mathrm{w}}}}{\omega_{\mathrm{w}}^{\beta_{\mathrm{w}}}\left(1+\mathrm{C}_{\mathrm{w}} \bar{s}^{\left.\beta_{\mathrm{w}}\right)}\right.}\right)^{\frac{\lambda_{s}}{\beta_{\mathrm{w}} \mathrm{m}_{\mathrm{w}}}}\right)^{-\mathrm{m}_{\mathrm{w}}}
$$

where $C_{w}$ is a constant of integration greater than or equal to zero (see Appendix $B$ ). The value of $C_{w}$ is obtained by imposing a suitable boundary condition, e.g. it can be calculated from the initial soil state by substituting the initial values of degree of saturation and scaled suction in equation (25) (or, equivalently, in equation (B3) of Appendix B).

By substituting the definition of scaled suction $\bar{s}=s e^{\frac{1}{\lambda_{s}}}$ inside equation (25), we obtain the following expression for the generic wetting surface in the $S_{r}-s-e$ space:

$$
\left(S_{r}\right)_{\mathrm{w}}=\left(1+\left(\frac{\left(s e^{\frac{1}{\lambda_{s}}}\right)^{\beta_{\mathrm{w}}}}{\left.\omega_{\mathrm{w}}^{\beta_{\mathrm{w}}\left(1+\mathrm{C}_{\mathrm{w}}\left(s e^{\frac{1}{\lambda_{s}}}\right)^{\beta_{\mathrm{w}}}\right.}\right)}\right)^{\frac{\lambda_{s}}{\beta_{\mathrm{w}} \mathrm{m}_{\mathrm{w}}}}\right)^{-\mathrm{m}_{\mathrm{w}}}
$$

As for the drying case, equation (26) describes all wetting paths in the region of admissible states and reduces to the main surface of equation (6a) when $C_{w}$ is equal to zero. Equation (26) is the only equation 
needed to describe the wetting behaviour of the soil, with each wetting path being characterized by a different value of the constant $\mathrm{C}_{\mathrm{w}}$.

\section{MODEL CALIBRATION AND VALIDATION}

Two alternative strategies can be used to calibrate the proposed retention model.

The first strategy may be employed if the experimental data describe with sufficient accuracy the asymptotes of the main retention surfaces of the soil, i.e. if at least part of the experimental data lies sufficiently close to the asymptotes of the main drying and wetting surfaces. In this case, according to equation (7), the parameters $\omega_{\mathrm{i}}$ and $\lambda_{s}$ are determined as the intercept and slope, respectively, of the asymptotes of the experimental drying and wetting curves presented in terms of $\log e_{w}$ versus $\log s$ (recall that $\log e_{w}=\log S_{r} e=\log S_{r}+\log e$ ). Next, the parameter $\mathrm{m}_{\mathrm{i}}$ is obtained by fitting equation (8) to the difference $\Delta \log S_{r}$ between the experimental drying and wetting curves and their respective asymptotes, plotted against experimental values of $S_{r}$ (asymptotes are calculated by equation (7) using the experimental values of $e$ and $s$ ). Finally, the parameter $\beta_{\mathrm{i}}$ is defined by fitting equations (21) and (25) to drying and wetting paths inside the region between two main curves in the in the $S_{r}-\bar{s}$ plane.

The second calibration strategy consists in simply performing a least square regression of equations (21) and (25) to all available data by using a suitable software to simultaneously optimize parameters $\omega_{\mathrm{i}}, \lambda_{s}, \mathrm{~m}_{\mathrm{i}}$ and $\beta_{\mathrm{i}}$. For each test used during calibration, the integration constant $\mathrm{C}_{\mathrm{i}}$ of equation (21) or (25) may be treated as an additional fitting variable. If the test consists of one or more wetting-drying cycles, only the integration constant $\mathrm{C}_{\mathrm{i}}$ of the first drying or wetting path is treated as a fitting variable. Instead, the integration constants of the subsequent drying and wetting paths are calculated by imposing the continuity of the soil path at the reversal points of the cycle, i.e. by using equation (B1) and (B3) of Appendix B, respectively. 
The first calibration strategy provides a clearer physical interpretation of model parameters, yet the second calibration strategy might lead to better predictions because all parameter values are simultaneously optimized to reproduce soil behaviour. Note that, for both calibration strategies, all parameter values are subjected to the restrictions of equations (14), (15) and (16).

In the following part of this section, model predictions are validated against two different experimental data sets published in the literature. The first data set is taken from Romero and Vaunat (2000), who performed suction controlled tests on statically compacted samples of a moderately swelling clay (20\%$30 \%$ kaolinite, $20 \%-30 \%$ illite and $10 \%-20 \%$ smectite) with a liquid limit of $56 \%$ and a plastic limit of $29 \%$. The second data set is taken from Sun et al. (2007), who performed suction controlled tests on statically compacted Pearl Clay (50\% silt and 50\% clay) with a liquid limit of $49 \%$ and a plastic limit of $27 \%$. Both the above data sets refer to fine grained materials and further validation is therefore needed to demonstrate the applicability of the proposed model to coarser soils.

Model predictions are calculated by using standard spreadsheet software (e.g. Microsoft Excel). The soil is assumed to move along a drying path if the value of scaled suction increases, and along a wetting path if the value of scaled suction decreases. The value of scaled suction is calculated from the experimental values of void ratio and suction and is then used to predict the variation of degree of saturation according to the model. The use of the experimental values of void ratio is acceptable in the present context to validate the capabilities of the proposed model. However, in the case of practical applications, experimental values of void ratio are usually unknown and a mechanical law must therefore be introduced for predicting the changes of void ratio during generic stress/suction paths. 
All parameter values were simultaneously determined by fitting at the same time two isochoric dryingwetting cycles at void ratios of 0.63 and 0.92 , respectively (i.e. the second of the above mentioned calibration strategies was used). Fig. 7 shows the two drying-wetting cycles together with the best fit curves. The resulting parameter values are summarised in Table 1, which also gives the values of the integration constant $C_{i}$ of each drying and wetting path. In each of the two cycles, the integration constant $\mathrm{C}_{\mathrm{d}}$ of the initial drying path is treated as an additional independent fitting variable, similar to other model parameters. Instead, the integration constant $\mathrm{C}_{\mathrm{w}}$ of the subsequent wetting path is calculated from equation (B3) of Appendix B by imposing the continuity of the soil path at the reversal point of the cycle, and therefore depends on model parameters. Inspection of Table 1 indicates that all integration constants $\mathrm{C}_{\mathrm{i}}$ are nearly zero, which confirms that the drying and wetting paths of both cycles lie very close to the main surfaces, in agreement with the findings of Romero and Vaunat (2000).

Model predictions were subsequently validated against two additional tests not used during calibration. The comparisons between predictions and experiments are presented in the $S_{r}-\log s$ and $S_{r}-e$ planes.

In the first test (Fig. 8), a low-porosity specimen was subjected to a constant isotropic net stress of 0.085 $\mathrm{MPa}$ and wetted from an initial suction of $1.9 \mathrm{MPa}$ to a suction of $0.01 \mathrm{MPa}$ (path A-B). This was followed by a drying-wetting cycle between suctions of $0.01 \mathrm{MPa}$ and $0.45 \mathrm{MPa}$ (path $\mathrm{B}-\mathrm{C}-\mathrm{D}$ ) and by another drying path to a suction of $0.20 \mathrm{MPa}$ (path D-E). Finally, the specimen was subjected to an isotropic loadingunloading cycle (path E-F-G) between mean net stresses of $0.085 \mathrm{MPa}$ and $0.8 \mathrm{MPa}$ at a constant suction of $0.20 \mathrm{MPa}$. 
In the second test (Fig. 9), a high-porosity specimen was subjected to oedometric loading with measurement of radial stresses. The specimen was first wetted, under a constant vertical net stress of 0.60 $\mathrm{MPa}$, from an initial suction of $1.9 \mathrm{MPa}$ to a suction of $0.01 \mathrm{MPa}$ (path $\mathrm{A}-\mathrm{B})$. This was followed by a dryingwetting cycle between suctions of $0.45 \mathrm{MPa}$ and $0.01 \mathrm{MPa}$ (path $\mathrm{B}-\mathrm{C}-\mathrm{D}$ ) and a drying path to a suction of 0.20 MPa (path D-E). The last part of the test consisted in an oedometric loading-unloading-reloading cycle at a constant suction of $0.20 \mathrm{MPa}(\mathrm{E}-\mathrm{F}-\mathrm{G}-\mathrm{H})$.

In the simulations, the value of the constant of integration $\mathrm{C}_{\mathrm{w}}$ of the first wetting path was obtained from equation (B3) of Appendix B by imposing that the start point of the predicted curve coincides with the start point of the experimental curve. The constants of integrations $C_{i}$ of the subsequent drying or wetting paths were instead calculated from equations (B1) or (B3) by imposing the continuity of the soil path at the reversal points of the cycle. Inspection of Figs. 8 and 9 indicates that the model is capable of adequately representing experimental behaviour, including the scanning behaviour between main surfaces. Yet, one aspect of the model that requires further refinement relates to the effect of deformation on degree of saturation. This is evident in the simulations of the loading-unloading cycles of Figs. 8 and 9, where changes of degree of saturation are underestimated by the model, especially during the first loading. Indeed, as it will be shown in the next section, the model accurately captures the variation of degree of saturation during main compression at constant suction but reproduces less well the effect of deformation on degree of saturation along soil paths between the main surfaces.

DATA BY SUN ET AL. (2007)

Also in this case parameter values were determined according to the second calibration strategy by fitting a single test in which a specimen with an initial void ratio of 1.78 was subjected to two consecutive dryingwetting cycles under a constant isotropic net stress of $0.020 \mathrm{MPa}$. Fig. 10 presents the experimental data 
together with the best fit curve computed by the model in the $S_{r}-s$ plane, while Table 2 summarizes the corresponding parameter values and integration constants. Note that, unlike the previous calibration based on data by Romero and Vaunat (2000), in this case the void ratio is not constant during the test and therefore the curves shown in Fig. 10 are not isochoric drying and wetting curves.

As for the data by Romero and Vaunat (2000), the integration constant $C_{d}$ of the initial drying path is treated as an independent fitting variable while the integration constants $C_{i}$ of the subsequent wetting and drying paths are calculated from equations (B1) and (B3) by imposing the continuity of the soil path at reversal points. In Table 2 , the constants of integration $C_{d}$ of the two drying paths are relatively large suggesting that these paths start from a point that is relatively distant from the main drying surface and converge towards the main drying surface only when suction grows large. Conversely, the constants of integration $\mathrm{C}_{\mathrm{w}}$ of the two wetting paths are relatively small, suggesting that both these paths lie close to the main surface at the start of wetting.

Model predictions were subsequently validated against another test not used during calibration (Fig. 11). In this test, a specimen was subjected to a constant net isotropic stress of $0.020 \mathrm{MPa}$ and wetted from a suction of $0.196 \mathrm{MPa}$ to a suction of $0.002 \mathrm{MPa}$ (path A-B) followed by a drying path from $0.002 \mathrm{MPa}$ to $0.490 \mathrm{MPa}$ (path B-C) and finally wetted from $0.490 \mathrm{MPa}$ to $0.002 \mathrm{kPa}$ (path C-D).

As before, the constant of integration $\mathrm{C}_{\mathrm{w}}$ of the first wetting path was obtained by imposing that the predicted and experimental curves coincide at the start of the test, while the constants of integrations $\mathrm{C}_{\mathrm{i}}$ of the subsequent drying or wetting paths were calculated by imposing the continuity of the soil path at reversal points. 
Inspection of Fig. 11 indicates that the model captures reasonably well the experimental behaviour, though the quality of the predictions is worse than in the case of Romero and Vaunat (2000). In both the first and second wetting paths, the model overestimates degree of saturation at low suctions. In particular, as suction tends to zero, the experimental value of degree of saturation stays at a level slightly smaller than one while the model predicts full saturation. This might be due to air being trapped into the sample during the wetting branch of the test, a phenomenon that might occur also in full-scale problems. Note also that the two tests used for calibration and validation, respectively, cover different ranges of void ratios (1.11 to 1.78 for the calibration test and 1.03 to 1.09 for the validation test). This is different from the case of Romero and Vaunat (2000), where the range of void ratio was approximately the same for both calibration and validation tests (the two calibration tests were performed at constant void ratios of 0.63 and 0.92 , respectively, while, in the validation tests, the void ratio varied between 0.58 to 0.88 ).

Finally, Sun et al. (2007) performed four triaxial tests at a constant suction of $0.147 \mathrm{MPa}$, namely two isotropic compression tests, where specimens with initial void ratios of 1.40 and 1.24 were loaded up to net stresses of $0.40 \mathrm{MPa}$ and $0.60 \mathrm{MPa}$, respectively, and two triaxial tests, where specimens with initial void ratios of 1.34 and 1.65 were isotropically compressed up to $0.20 \mathrm{MPa}$ and then sheared at constant mean net stress. Fig. 12 presents the results from these four tests and shows that, as the void ratio reduces, the degree of saturation increases along the same straight line in the $\log S_{r}-\log e$ plane. This linear response indicates that all four specimens lie, at the start of the test, close to the log-linear asymptotic plane of the main wetting surface. The degree of saturation subsequently increases along the same main isosuction compression curve at a constant suction of $0.147 \mathrm{MPa}$ while remaining near the log-linear asymptote. Fig. 12 also shows that the data points can be reasonably interpolated by a line with slope $\frac{\mathrm{d} \log S_{r}}{\mathrm{~d} \log e}=-1$, which supports the earlier assumption of $\lambda_{e \mathrm{i}}=1$ in equation (5). 
It is interesting to note that, in the calibration test of Fig. 10, the slopes of the two wetting paths are less well predicted than those of the two drying paths, which might also affect calculation of water flow in coupled analyses (e.g. Wong et al., 1998). As mentioned earlier, one possible explanation for this behaviour is that the effect of deformation on degree of saturation is less accurately described in the region between the main surfaces (Fig. 10) than near the main surfaces (Fig. 12).

\section{CONCLUSIONS}

The paper presents a soil water retention model which takes into account the effects of both hydraulic hysteresis and pore deformation on the variation of degree of saturation. The model is based on the definition of two bounding surfaces, i.e. a main drying surface and a main wetting surface, which delimit the region of attainable soil states in the space of degree of saturation, suction and void ratio. The two main surfaces are recast as curves in the plane of degree of saturation and scaled suction, where the scaled suction is an auxiliary variable defined in terms of void ratio and suction. Drying paths correspond to an increase of scaled suction while wetting paths correspond to a decrease of scaled suction. The introduction of scaled suction therefore simplifies the definition of drying or wetting paths by taking into account the effects of both suction and void ratio.

Only two equations are required to describe the soil retention behaviour inside the region delimited by the two scaled main curves, one equation for drying paths and one equation for wetting paths. These two equations are obtained by integrating, in a closed form, the corresponding derivatives of degree of saturation with respect to scaled suction. These derivatives are defined to ensure a smooth, asymptotic transition of the drying and wetting paths towards the respective main curves. The integration constants are different for each wetting or drying path and are defined by imposing that the relevant curve passes through a point with known values of degree of saturation and scaled suction. The main advantage of the proposed model is that all wetting and drying paths can be described by closed form equations which 
uniquely relate the degree of saturation to the scaled suction and, hence, uniquely relate degree of saturation to suction and void ratio. This feature significantly facilitates the implementation of the model into numerical codes.

The model is formulated in terms of seven independent parameters, whose values can be obtained from a single drying-wetting cycle by using two alternative calibration strategies. All model parameters have a clear physical interpretation and their values are subjected to a number of restrictions to ensure physical consistency. Parameter values have been calibrated on the basis of two different laboratory data sets published in the literature and the resulting predictions have been validated against additional data from the same sets but not used during calibration. The predicted variation of degree of saturation has been calculated by using experimental values of void ratio and suction as input variables to the model. However, in most real boundary value problems, the experimental values of void ratio are unknown and the proposed model must therefore be coupled with a suitable stress-strain law to predict the variation of void ratio during changes of stress and suction.

\section{APPENDIX A}

For any given pair of $S_{r}$ and $e$, the ratio between the two values of $s$ calculated by equation (6a) on the main drying and wetting surfaces, respectively, must be greater or equal to one. This restriction leads, after some algebraic manipulations, to the following inequality between model parameters, which must be satisfied for any value of $S_{r}$ and $e$ :

$$
\frac{\omega_{\mathrm{w}}}{\omega_{\mathrm{d}}} \leq \frac{\left(1-S_{r}^{\frac{1}{m_{d}}}\right)^{\frac{m_{d}}{\lambda_{s d}}}}{\left(1-S_{r}{ }^{\frac{1}{m_{\mathrm{w}}}}\right)^{\frac{m_{\mathrm{w}}}{\lambda_{s \mathrm{w}}}}}\left(S_{r} e\right)^{-\frac{\lambda_{s w}-\lambda_{s d}}{\lambda_{s w} \lambda_{s d}}}
$$


In particular, equation (A1) must be verified at the two extremes of the range of $S_{r}$, i.e. for $S_{r} \rightarrow 0$ and $S_{r} \rightarrow 1$

Case of $S_{r} \rightarrow 0$

When $S_{r} \rightarrow 0$, equation (A1) is verified for any value of $e$ provided that the exponent of the power term $\left(S_{r} e\right)^{-\frac{\lambda_{s \mathrm{w}}-\lambda_{s \mathrm{~d}}}{\lambda_{s \mathrm{w}} \lambda_{s \mathrm{~d}}}}$ has negative sign, i.e. provided that $\lambda_{s \mathrm{w}}>\lambda_{s \mathrm{~d}}$ or, in other words, provided that $\frac{\lambda_{s \mathrm{w}}}{\lambda_{s \mathrm{~d}}}>1$. If $\frac{\lambda_{s \mathrm{w}}}{\lambda_{s \mathrm{~d}}}=1$, the exponent of the power term $\left(S_{r} e\right)^{-\frac{\lambda_{s \mathrm{w}}-\lambda_{s \mathrm{~d}}}{\lambda_{s \mathrm{w}} \lambda_{s \mathrm{~d}}}}$ is equal to zero and equation (A1) is satisfied only if the additional condition $\frac{\omega_{\mathrm{w}}}{\omega_{\mathrm{d}}} \leq 1$ is simultaneously verified. Finally, if $\frac{\lambda_{s \mathrm{w}}}{\lambda_{s d}}<1$, the exponent of the power $\operatorname{term}\left(S_{r} e\right)^{-\frac{\lambda_{s \mathrm{w}}-\lambda_{s \mathrm{~d}}}{\lambda_{s \mathrm{w}} \lambda_{s \mathrm{~d}}}}$ has positive sign and equation (A1) is never satisfied.

Case of $S_{r} \rightarrow 1$

Let us first pose $S_{r}=(1-u)$ which yields the following alternative form of equation (A1) in terms of the auxiliary variable $u$ :

$$
\frac{\omega_{\mathrm{w}}}{\omega_{\mathrm{d}}} \leq \frac{\left(1-(1-u)^{\frac{1}{\mathrm{~m}_{\mathrm{d}}}}\right)^{\frac{\mathrm{m}_{\mathrm{d}}}{\lambda_{s d}}}}{\left(1-(1-u)^{\frac{1}{\mathrm{~m}_{\mathrm{w}}}}\right)^{\frac{\mathrm{m}_{\mathrm{w}}}{\lambda_{s w}}}}((1-u) e)^{-\frac{\lambda_{s w}-\lambda_{s d}}{\lambda_{s \mathrm{w}} \lambda_{s d}}}
$$


Equation (A2) is now rewritten by replacing the two expressions inside the brackets at the numerator and denominator of the right hand side with a first order Taylor series approximation at $u=0$ :

$$
\frac{\omega_{\mathrm{w}}}{\omega_{\mathrm{d}}} \leq \frac{\left(\frac{1}{\mathrm{~m}_{\mathrm{d}}} u+o(u)\right)^{\frac{\mathrm{m}_{\mathrm{d}}}{\lambda_{s d}}}}{\left(\frac{1}{\mathrm{~m}_{\mathrm{w}}} u+o(u)\right)^{\frac{\mathrm{m}_{\mathrm{w}}}{\lambda_{s \mathrm{w}}}}((1-u) e)^{-\frac{\lambda_{s w}-\lambda_{s d}}{\lambda_{s \mathrm{w}} \lambda_{s d}}}}
$$

By neglecting the terms of second and higher order in the Taylor series approximation, equation (A3) is rewritten as:

$$
\frac{\omega_{\mathrm{w}}}{\omega_{\mathrm{d}}} \leq \frac{\left(\frac{1}{\mathrm{~m}_{\mathrm{d}}}\right)^{\frac{\mathrm{m}_{\mathrm{d}}}{\lambda_{s d}}}}{\left(\frac{1}{\mathrm{~m}_{\mathrm{w}}}\right)^{\frac{\mathrm{m}_{\mathrm{w}}}{\lambda_{s \mathrm{w}}}}} u^{\frac{\mathrm{m}_{\mathrm{d}}}{\lambda_{s d}}} \frac{\mathrm{m}_{\mathrm{w}}}{\lambda_{s \mathrm{w}}}((1-u) e)^{-\frac{\lambda_{s w}-\lambda_{s d}}{\lambda_{s w} \lambda_{s d}}}
$$

When $S_{r} \rightarrow 1$, then $u \rightarrow 0^{+}$and equation (A4) is satisfied for any value of $e$ provided that the exponent of the power term $u^{\frac{\mathrm{m}_{\mathrm{d}}}{\lambda_{s d}}-\frac{\mathrm{m}_{\mathrm{w}}}{\lambda_{s \mathrm{w}}}}$ is negative, i.e. provided that $\frac{\mathrm{m}_{\mathrm{w}}}{\lambda_{s \mathrm{w}}}>\frac{\mathrm{m}_{\mathrm{d}}}{\lambda_{s \mathrm{~d}}}$ or, alternatively, $\frac{\mathrm{m}_{\mathrm{w}}}{\mathrm{m}_{\mathrm{d}}}>\frac{\lambda_{s \mathrm{w}}}{\lambda_{s \mathrm{~d}}}$. If $\frac{\mathrm{m}_{\mathrm{w}}}{\mathrm{m}_{\mathrm{d}}}=\frac{\lambda_{s \mathrm{w}}}{\lambda_{s \mathrm{~d}}}$, the exponent of the power term $u^{\frac{m_{d}}{\lambda_{s d}}}-\frac{m_{w}}{\lambda_{s w}}$ is equal to zero and equation (A4) is satisfied only if the additional inequality $\frac{\omega_{\mathrm{w}}}{\omega_{\mathrm{d}}} \leq\left(\frac{\mathrm{m}_{\mathrm{w}}}{\mathrm{m}_{\mathrm{d}}}\right)^{\frac{\mathrm{m}_{\mathrm{w}}}{\lambda_{s \mathrm{w}}}} e^{-\frac{\lambda_{s \mathrm{w}}-\lambda_{s \mathrm{~d}}}{\lambda_{s \mathrm{w}} \lambda_{s \mathrm{~d}}}}$ is simultaneously verified over the experimental range of $e$. Finally, when $\frac{m_{w}}{m_{d}}<\frac{\lambda_{s w}}{\lambda_{s d}}$, the exponent of the power term $u^{\frac{m_{d}}{\lambda_{s d}}-\frac{m_{w}}{\lambda_{s w}}}$ is positive and equation (A4) is never satisfied. 
By taking into account both the above cases of $S_{r} \rightarrow 0$ and $S_{r} \rightarrow 1$, the following constraint must be imposed on model parameters:

$$
\frac{\mathrm{m}_{\mathrm{w}}}{\mathrm{m}_{\mathrm{d}}} \geq \frac{\lambda_{s \mathrm{w}}}{\lambda_{s \mathrm{~d}}} \geq 1
$$

If the right hand side relationship of equation (A5) is verified with the equal sign (i.e. $\frac{\lambda_{s w}}{\lambda_{s d}}=1$ ), the following additional restriction must also be verified:

$$
\frac{\omega_{\mathrm{w}}}{\omega_{\mathrm{d}}} \leq 1
$$

Similarly, if the left hand side relationship of equation (A5) is verified with the equal sign (i.e. $\frac{m_{w}}{m_{d}}=\frac{\lambda_{s w}}{\lambda_{s d}}$ ), the following additional restriction must be verified over the experimental range of $e$ :

$$
\frac{\omega_{\mathrm{w}}}{\omega_{\mathrm{d}}} \leq\left(\frac{\lambda_{s \mathrm{w}}}{\lambda_{s \mathrm{~d}}}\right)^{\frac{\mathrm{m}_{\mathrm{w}}}{\lambda_{s \mathrm{w}}}} e^{-\frac{\lambda_{s \mathrm{w}}-\lambda_{s \mathrm{~d}}}{\lambda_{s \mathrm{w}} \lambda_{s \mathrm{~d}}}}
$$

Let us now note that, if $\frac{\lambda_{s w}}{\lambda_{s d}}=1$, equation (A7) reduces to equation (A6). So we can conclude that, if any of the two relationships in equation (A5) is verified with the equal sign, equation (A7) must be fulfilled as an additional condition.

\section{APPENDIX B}

The constant of integration $C_{d}$ is calculated from equation (21) by imposing that the drying scaled curve passes through a known point of coordinates $\left\{S_{r}, \bar{s}\right\}$ : 


$$
C_{d}=\omega_{d}^{\beta_{d}}\left(S_{r}^{-\frac{1}{m_{d}}}-1\right)^{\frac{\beta_{d} m_{d}}{\lambda_{s}}}-\bar{s}^{\beta_{d}}
$$

By taking into account equation (18), equation (B1) can be rewritten as:

$$
C_{\mathrm{d}}=\bar{s}_{\mathrm{d}} \beta_{\mathrm{d}}-\bar{s}^{\beta_{\mathrm{d}}}
$$

where $\bar{s}_{\mathrm{d}}$ is the image value of scaled suction, i.e. the value of scaled suction on the main drying scaled curve corresponding to the current value of $S_{r}$. Given that the image value of scaled suction on the main drying scaled curve is always greater or equal to the current value of scaled suction, the constant $C_{d}$ in equation (B2) is always greater or equal than zero. In particular, $C_{d}$ is equal to zero when the current and image values of scaled suction are identical, i.e. when the soil state lies on the main drying scaled curve.

Similarly, the constant of integration $\mathrm{C}_{\mathrm{w}}$ is calculated from equation (25) by imposing that the curve passes through a known point of coordinates $\left\{S_{r}, \bar{s}\right\}$ :

$$
\mathrm{C}_{\mathrm{w}}=\frac{1}{\omega_{\mathrm{w}}^{\beta_{\mathrm{w}}}}\left(S_{r}^{-\frac{1}{\mathrm{~m}_{\mathrm{w}}}}-1\right)^{-\frac{\beta_{\mathrm{w}} \mathrm{m}_{\mathrm{w}}}{\lambda_{s \mathrm{w}}}}-\frac{1}{\bar{s}^{\beta_{\mathrm{w}}}}
$$

Again, by taking into account equation (18), equation (B3) can be rewritten as::

$$
\mathrm{C}_{\mathrm{w}}=\frac{1}{\bar{s}_{\mathrm{w}} \beta_{\mathrm{w}}}-\frac{1}{\bar{s}^{\beta_{\mathrm{w}}}}
$$

where $\bar{s}_{\mathrm{W}}$ is the image value of scaled suction this time on the main wetting scaled curve. Given that the image value of scaled suction on the main wetting scaled curve is always smaller or equal to the current 
value of scaled suction, the constant $\mathrm{C}_{\mathrm{w}}$ in equation (B4) is always greater or equal than zero. In particular, $\mathrm{C}_{\mathrm{w}}$ is equal to zero when the soil state lies on the main wetting scaled curve. 


\section{REFERENCES}

Barrera, M. (2002). Estudio experimental del comportamiento hidro-mecánico de suelos colapsables. PhD thesis, Universitat Politècnica de Catlunya, Barcelona, Spain - http://www.tdx.cat/TDX-0604102-095524.

Brooks, R.N. and Corey, A.T. (1964). Hydraulic properties of porous media. Colorado State University Hydrology Paper $n^{\circ} 3$.

Casini, F., Vaunat, J., Romero, E. and Desideri, A. (2012). Consequences on water retention properties of double-porosity features in a compacted silt. Acta Geotechnica 7:139-150 http://dx.doi.org/10.1007/s11440-012-0159-6.

Fredlund, D.G. and Xing, A.Q. (1994). Equations for the soil-water characteristic curve. Canadian Geotechnical Journal, 31(4):521-532.

Gallipoli, D. (2012). A hysteretic soil-water retention model accounting for cyclic variations of suction and void ratio. Géotechnique 62(7): 605-616 - http://dx.doi.org/10.1680/geot.11.P.007.

Gallipoli, D., Wheeler, S. and Karstunen, M. (2003). Modelling the variation of degree of saturation in a deformable unsaturated soil. Géotechnique 53(1): 105-112 - http://dx.doi.org/10.1680/geot.2003.53.1.105

Hu, R., Chen, Y.-F., Liu, H.-H. and Zhou, C.-B. (2013). A water retention curve and unsaturated hydraulic conductivity model for deformable soils: consideration of the change in pore-size distribution. Géotechnique, 63(16): 1389-1405 - http://dx.doi.org/10.1680/geot.12.P.182.

Khalili, N., Habte, M.A. and Zargarbashi, S. (2008). A fully coupled flow deformation model for cyclic analysis of unsaturated soils including hydraulic and mechanical hysteresis. Computers and Geotechnics 35(6): 872889.

Li, X.S. (2005). Modelling of hysteresis response for arbitrary wetting/drying paths. Computers and Geotechnics 32: 133-137.

Lloret, A., Villar, M.V., Sánchez, M., Gens, A., Pintado, X. and Alonso, E. E. (2003). Mechanical behaviour of heavily compacted bentonite under high suction changes. Géotechnique 53(1): 27-40 http://dx.doi.org/10.1680/geot.2003.53.1.27.

Mašín, D. (2010). Predicting the dependency of a degree of saturation on void ratio and suction using effective stress principle for unsaturated soils. International Journal for Numerical and Analytical Methods in Geomechanics, 34: 73-90.

Nuth, M. and Laloui, L. (2008). Advances in modelling hysteretic water retention curve in deformable soils. Computers and Geotechnics 35(6): 835-844.

Pedroso, D.M. and Williams, D.J. (2010). A novel approach for modelling soil-water characteristic curves with hysteresis. Computers and Geotechnics 37(3): 374-380.

Romero, E., Della Vecchia, G. and Jommi, C. (2011). An insight into the water retention properties of compacted clayey soils. Géotechnique 61(4):313-328 - http://dx.doi.org/10.1680/geot.2011.61.4.313. 
Romero, E. and Vaunat, J. (2000). Retention curve of deformable clays. In Proceedings of the international workshop on unsaturated soils, Trento, Italy, 91-106, Balkema, Rotterdam.

Russell, A.R. (2014). How water retention in fractal soils depends on particle and pore sizes, shapes, volumes and surface areas. Géotechnique, 64(5): 379 -390 - http://dx.doi.org/10.1680/geot.13.P.165.

Salager, S., El Youssoufi, M.S. and Saix, C. (2010). Definition and experimental determination of a soil-water retention surface. Canadian Geotechnical Journal. 47:609-622. http://dx.doi.org/10.1139/T09-123.

Salager, S., Nuth, M., Ferrari, A. and Laloui, L. (2013). Investigation into water retention behaviour of deformable soils. Canadian Geotechnical Journal, 50: 200-208 - http://dx.doi.org/10.1139/cgj-2011-0409.

Sun, D.A., Sheng, D.C., Cui, H.B., and Sloan, S.W. (2007). A density-dependent elastoplastic hydromechanical model for unsaturated compacted soils. International Journal for Numerical and Analytical Methods in Geomechanics, 31: 1257-1279.

Sun, D.A., Sheng, D., Xiang, L. and Sloan, S.W. (2008). Elastoplastic prediction of hydro-mechanical behaviour of unsaturated soils under undrained conditions. Computers and Geotechnics 35(6): 845-852.

Tarantino, A. (2009). A water retention model for deformable soils. Géotechnique 59(9): 751-762 http://dx.doi.org/10.1680/geot.7.00118.

Tsiampousi, A., Zdravković, L. and Potts, D.M. (2013). A three-dimensional hysteretic soil-water retention curve. Géotechnique 63(2): 155-164 - http://dx.doi.org/10.1680/geot.11.P.074.

Van Genuchten, M. T. (1980). A closed-form equation for predicting the hydraulic conductivity of unsaturated soil. Soil Science Society American Journal, 44: 892-898.

Wheeler, S.J., Sharma, R.S. and Buisson, M.S.R. (2003). Coupling of hydraulic hysteresis and stress-strain behaviour in unsaturated soils. Géotechnique 53(1): 41-54 - http://dx.doi.org/10.1680/geot.2003.53.1.41.

Wong, T. T., Fredlund, D. G., and Krahn, J. (1998). A numerical study of coupled consolidation in unsaturated soils. Canadian Geotechnical Journal, 35: 926-937.

Zhou, A. N., Sheng, D., Sloan, S. W., and Gens, A. (2012). Interpretation of unsaturated soil behaviour in the stress-saturation space, I: Volume change and water retention behaviours. Computers and Geotechnics, 43: 178-187. 


\section{LIST OF TABLES AND RELATIVE CAPTIONS}

\begin{tabular}{|c|c|c|c|}
\hline \multicolumn{2}{|c|}{ DRYING PATHS } & \multicolumn{2}{|c|}{ WETTING PATHS } \\
\hline \multicolumn{4}{|c|}{ Parameter values } \\
\hline $\mathrm{m}_{\mathrm{d}}$ & 0.238 & $\mathrm{~m}_{\mathrm{w}}$ & 0.625 \\
\hline$\lambda_{\mathrm{sd}}=\lambda_{\mathrm{s}}$ & 0.413 & $\lambda_{\mathrm{sw}-}=\lambda_{\mathrm{s}}$ & 0.413 \\
\hline$\omega_{\mathrm{d}}$ & $0.751 \mathrm{MPa}$ & $\omega_{\mathrm{w}}$ & $0.383 \mathrm{MPa}$ \\
\hline$\beta_{\mathrm{d}}$ & 0.832 & $\beta_{\mathrm{w}}$ & 1.38 \\
\hline \multicolumn{4}{|c|}{ Integration constant values } \\
\hline $\begin{array}{c}\mathrm{C}_{\mathrm{d}} \text { for } e=0.92 \\
\text { (independent } \\
\text { fitting parameter) }\end{array}$ & 0.328 & $\begin{array}{c}\mathrm{C}_{\mathrm{w}} \text { for } e=0.92 \\
\text { (dependent } \\
\text { parameter) }\end{array}$ & 0.0012 \\
\hline $\begin{array}{c}\mathrm{C}_{\mathrm{d}} \text { for } e=0.63 \\
\text { (independent } \\
\text { fitting parameter) }\end{array}$ & 0.0077 & $\begin{array}{c}\mathrm{C}_{\mathrm{w}} \text { for } e=0.63 \\
\text { (dependent } \\
\text { parameter) }\end{array}$ & 0.0039 \\
\hline
\end{tabular}

Table 1. Parameter values for Romero and Vaunat (2000) 


\begin{tabular}{|c|c|c|c|}
\hline \multicolumn{3}{|c|}{ DRYING PATHS } & \multicolumn{1}{|c|}{ WETTING PATHS } \\
\hline \multicolumn{4}{|c|}{ Parameter values } \\
\hline $\mathrm{m}_{\mathrm{d}}$ & 0.382 & $\mathrm{~m}_{\mathrm{w}}$ & 0.913 \\
\hline$\lambda_{\mathrm{sd}}=\lambda_{\mathrm{s}}$ & 0.894 & $\lambda_{\text {sw- }}=\lambda_{\mathrm{s}}$ & 0.894 \\
\hline$\omega_{\mathrm{d}}$ & $0.159 \mathrm{MPa}$ & $\omega_{\mathrm{w}}$ & $0.092 \mathrm{MPa}$ \\
\hline$\beta_{\mathrm{d}}$ & 2.97 & $\beta_{\mathrm{w}}$ & 2.01 \\
\hline \multicolumn{4}{|c|}{ Integration constant values } \\
\hline $\begin{array}{c}\mathrm{C}_{\mathrm{d}} \\
\text { (independent } \\
\text { fitting parameter) }\end{array}$ & $6.23 \times 10^{7}$ & $\begin{array}{c}\mathrm{C}_{\mathrm{w}} \\
\text { (dependent } \\
\text { parameter) }\end{array}$ & $3.64 \times 10^{-6}$ \\
\hline $\begin{array}{c}\mathrm{C}_{\mathrm{d}} \\
\text { (dependent } \\
\text { parameter) }\end{array}$ & $4.28 \times 10^{5}$ & $\begin{array}{c}\mathrm{C}_{\mathrm{w}} \\
\text { (dependent } \\
\text { parameter) }\end{array}$ & $1.45 \times 10^{-5}$ \\
\hline
\end{tabular}

Table 2. Parameter values for Sun et al. (2007) 


\section{LIST OF FIGURES AND RELATIVE CAPTIONS}

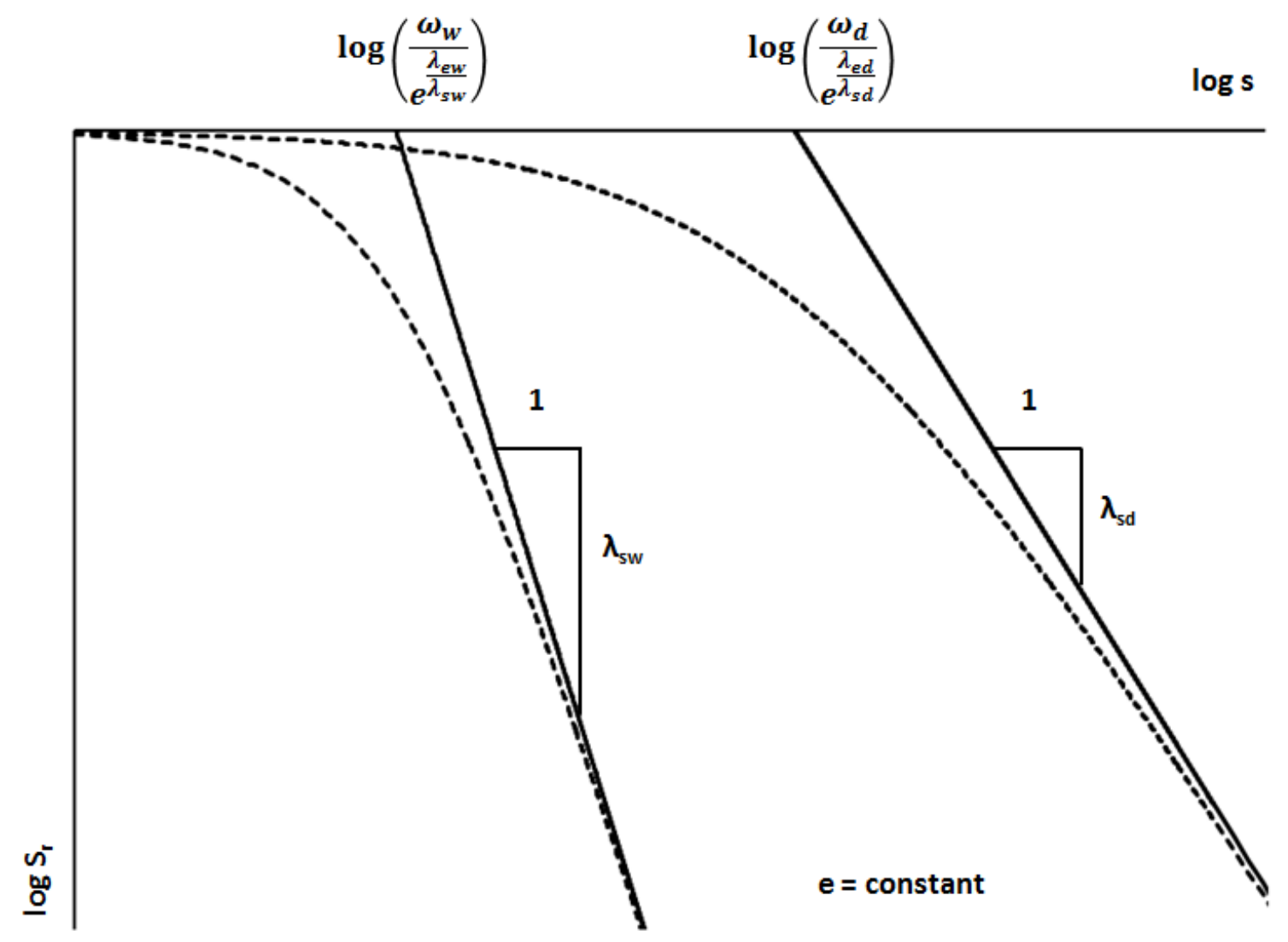

Figure 1. Slopes and intercepts of the asymptotes of the main isochoric desiccation and soaking curves in the $\log S_{r}-\log s$ plane. 


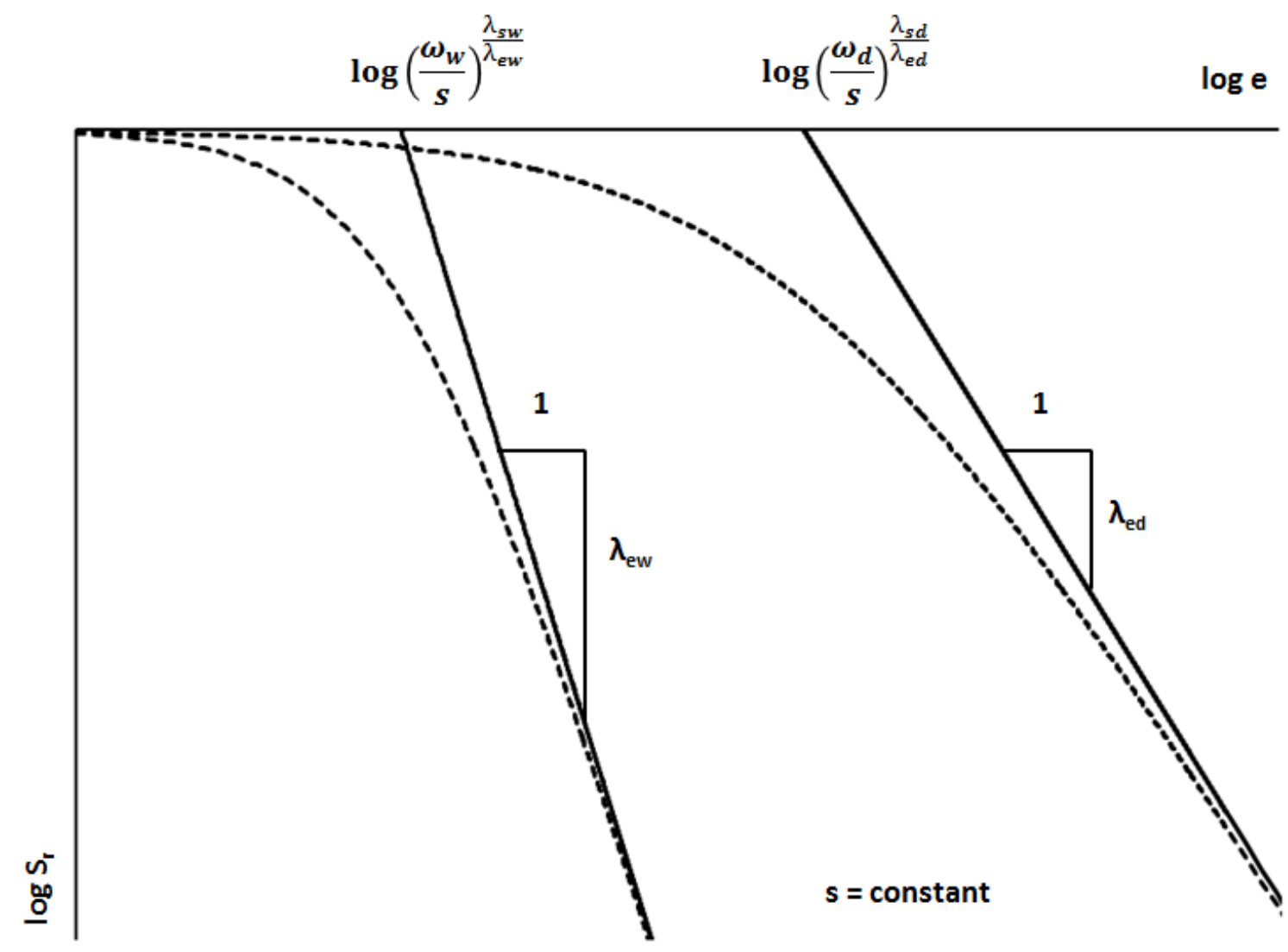

Figure 2. Slopes and intercepts of the asymptotes of the main isosuction swelling and compression curves in the $\log S_{r}-\log e$ plane. 


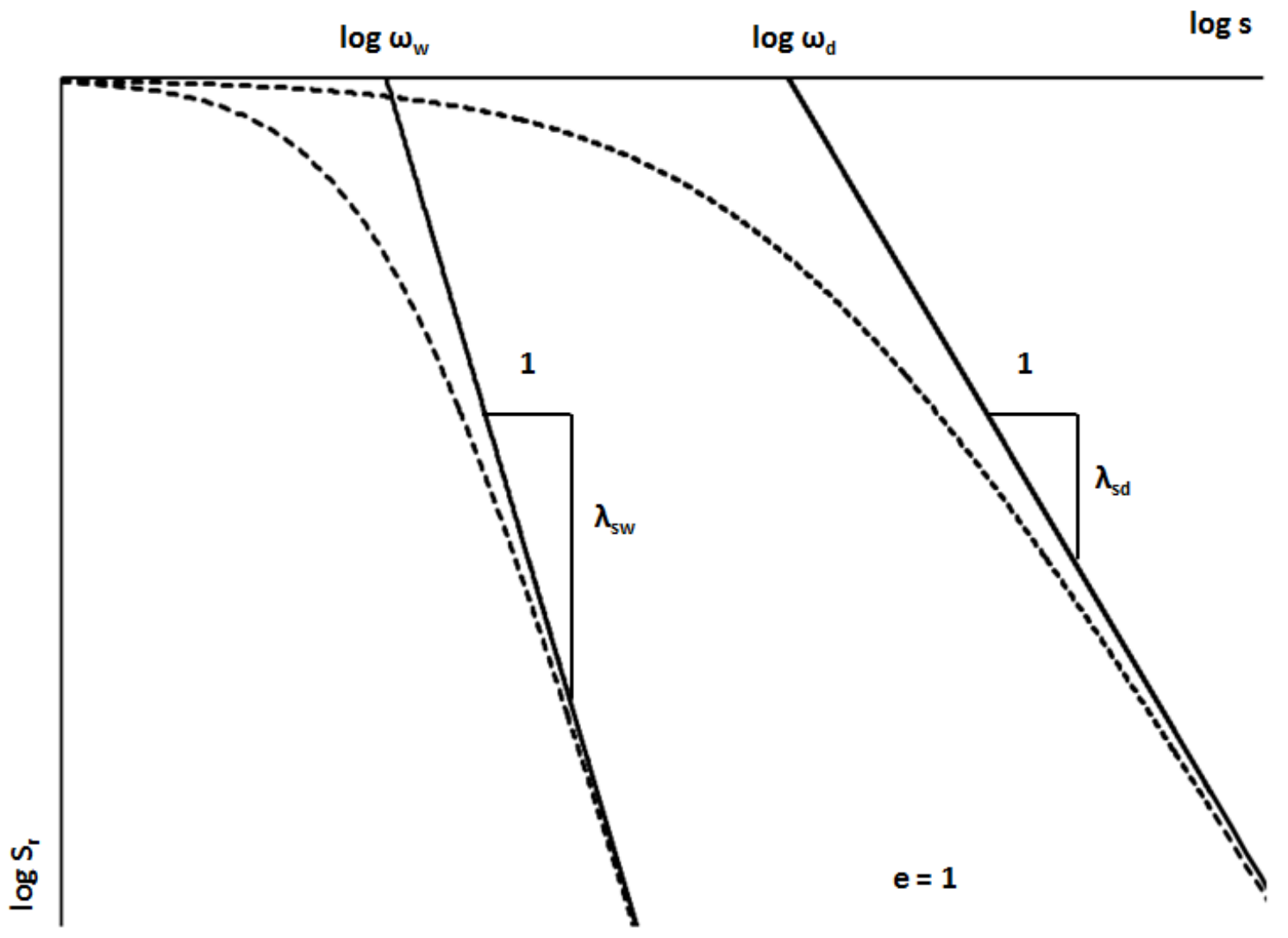

Figure 3. Slopes and intercepts of the asymptotes of the main isochoric desiccation and soaking curves in the $\log S_{r}-\log s$ plane at $e=1$. 

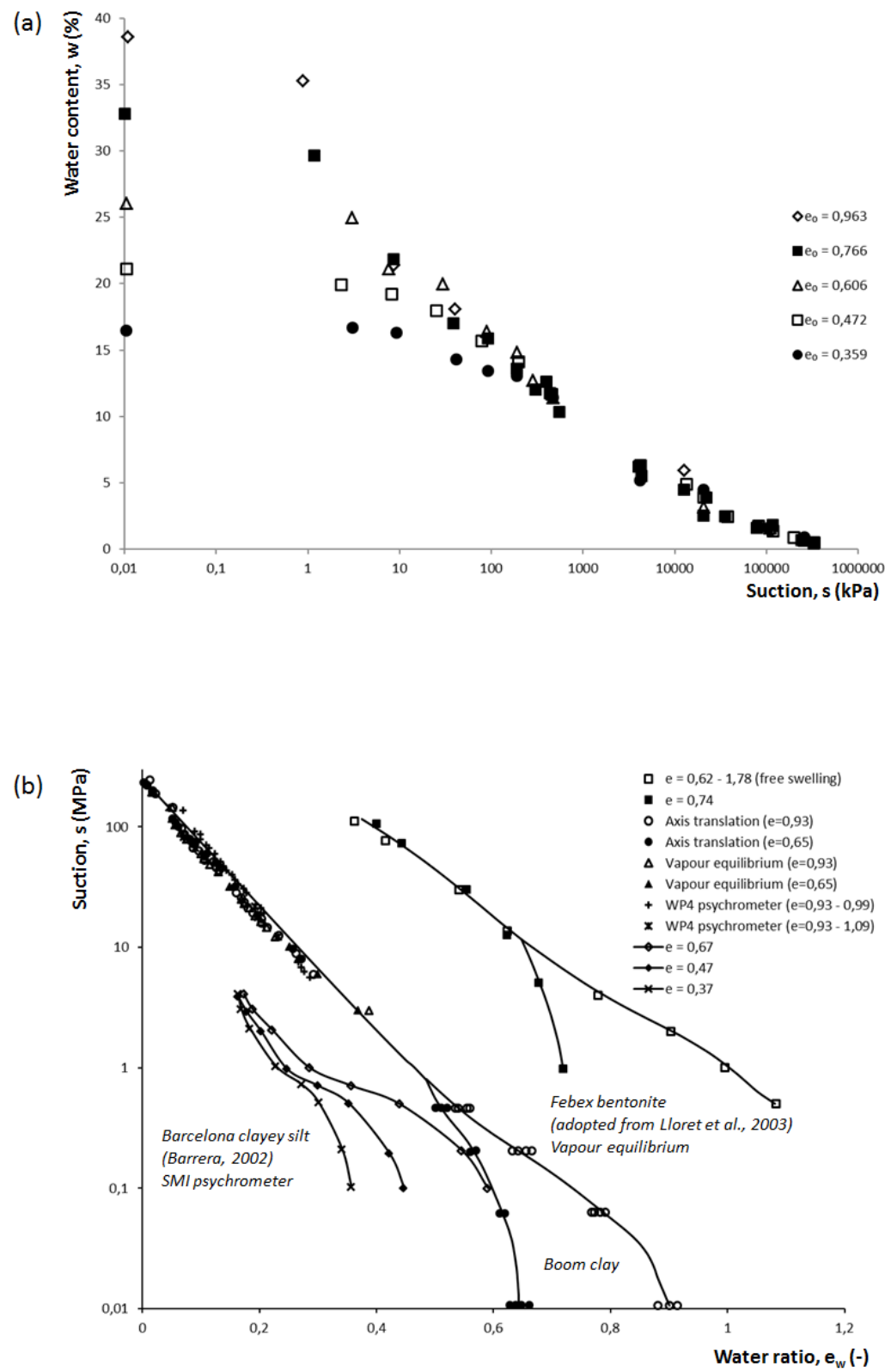

Figure 4. (a) Drying paths on a clayey silt at different void ratios (after Salager et al., 2013); (b) wetting paths on Boom Clay, Febex bentonite and Barcelona clayey silt at different void ratios (after Romero et al., 2011). 


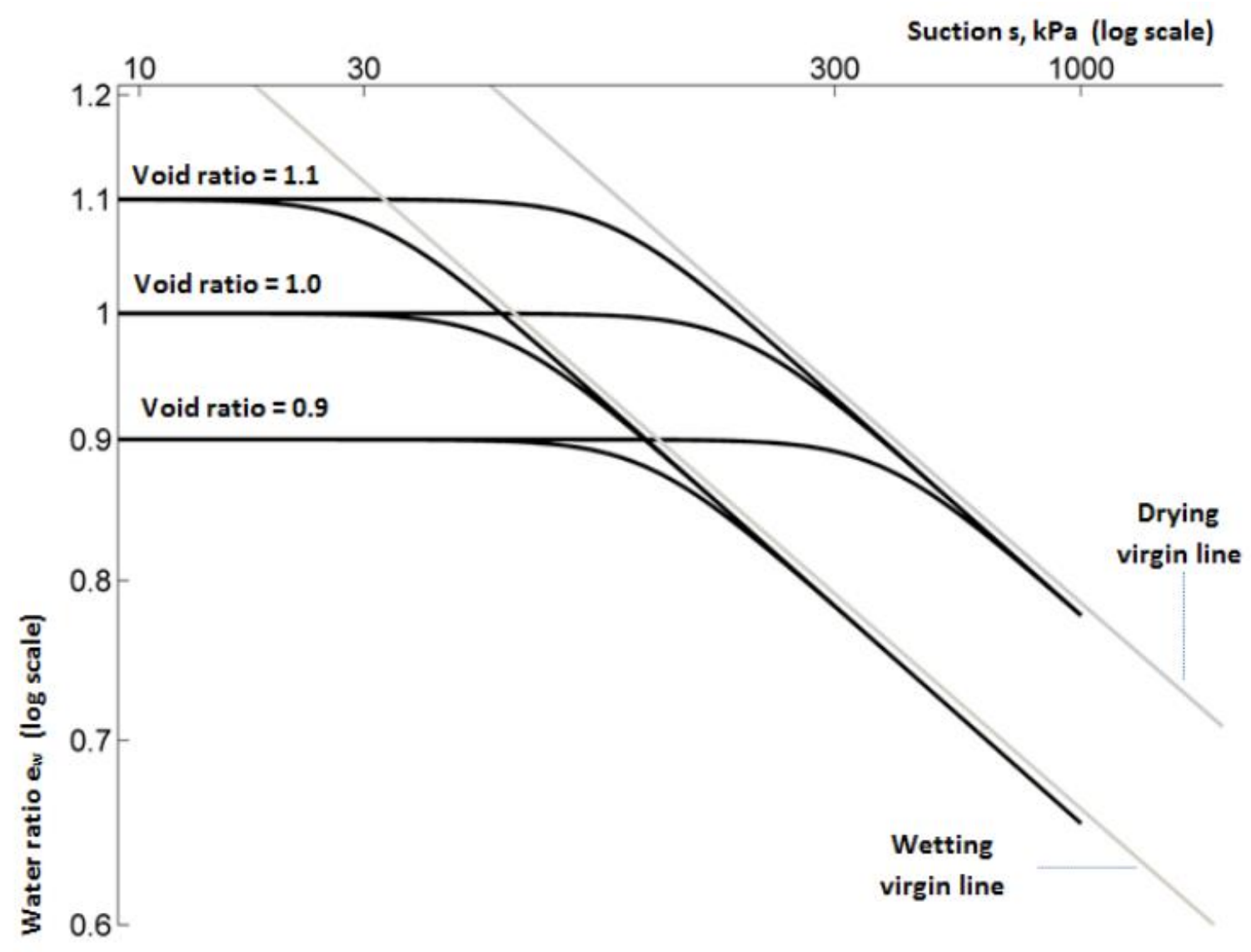

Figure 5. Typical curves of water ratio $e_{w}$ versus suction $s$ predicted by the model during drying and wetting at different constant values of void ratio (after Gallipoli, 2012). 
$\log s$

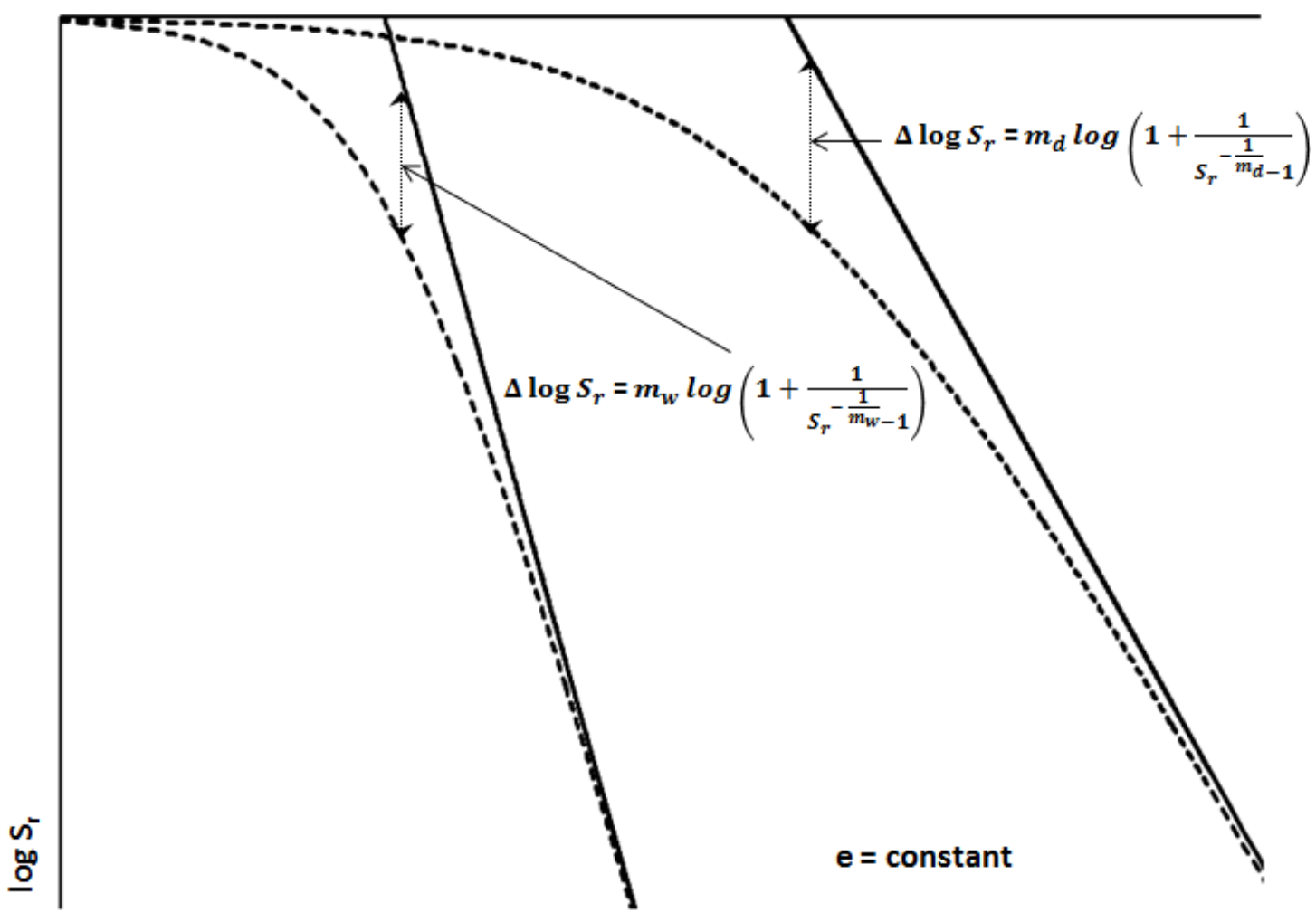

Figure 6. Deviation of the isochoric desiccation and soaking curves from their respective asymptotes. 

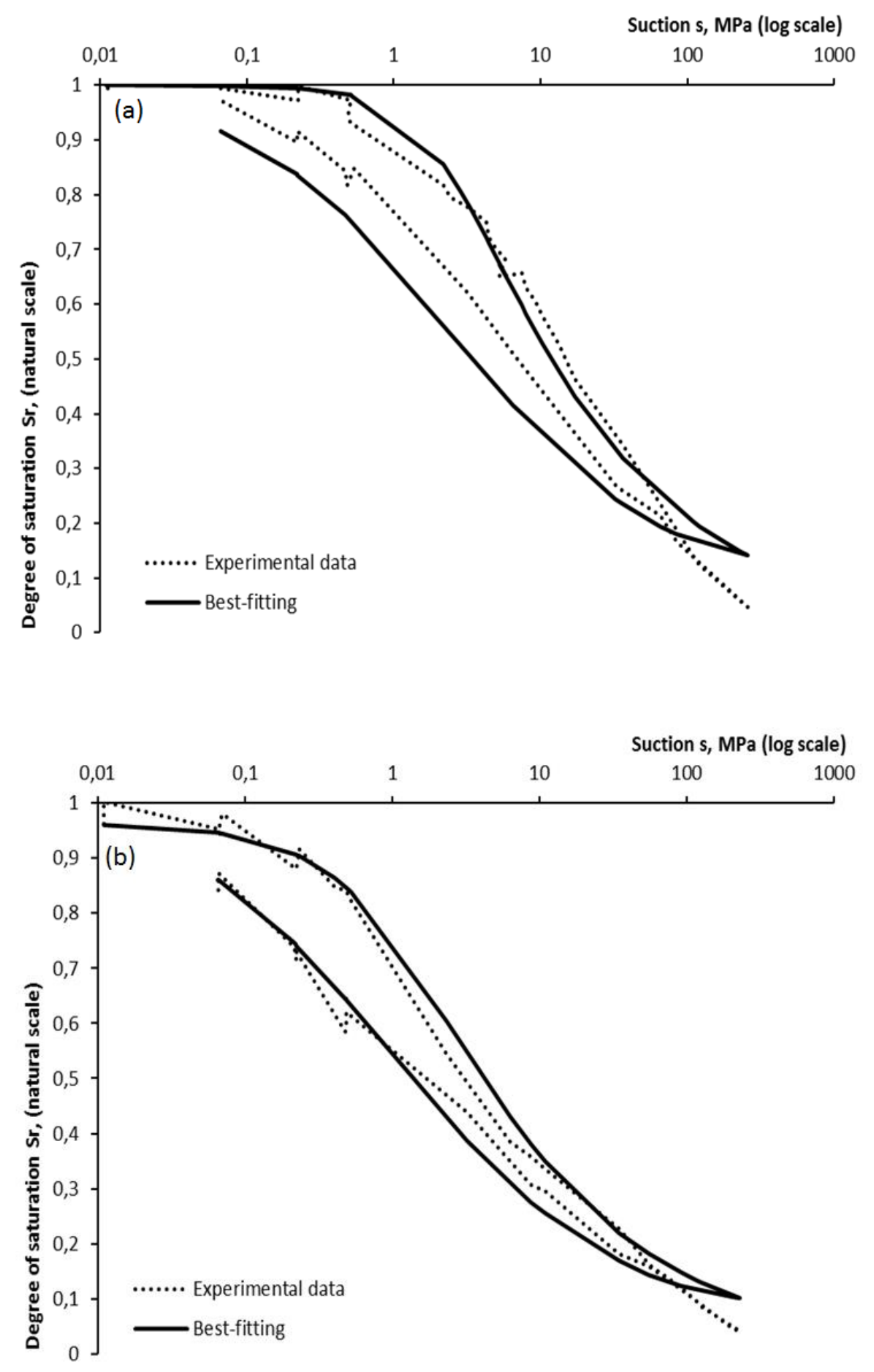

Figure 7. Model calibration through best-fitting of drying-wetting cycles at constant void ratio of (a) 0.63 and (b) 0.92 (experimental data from Romero and Vaunat, 2000). 

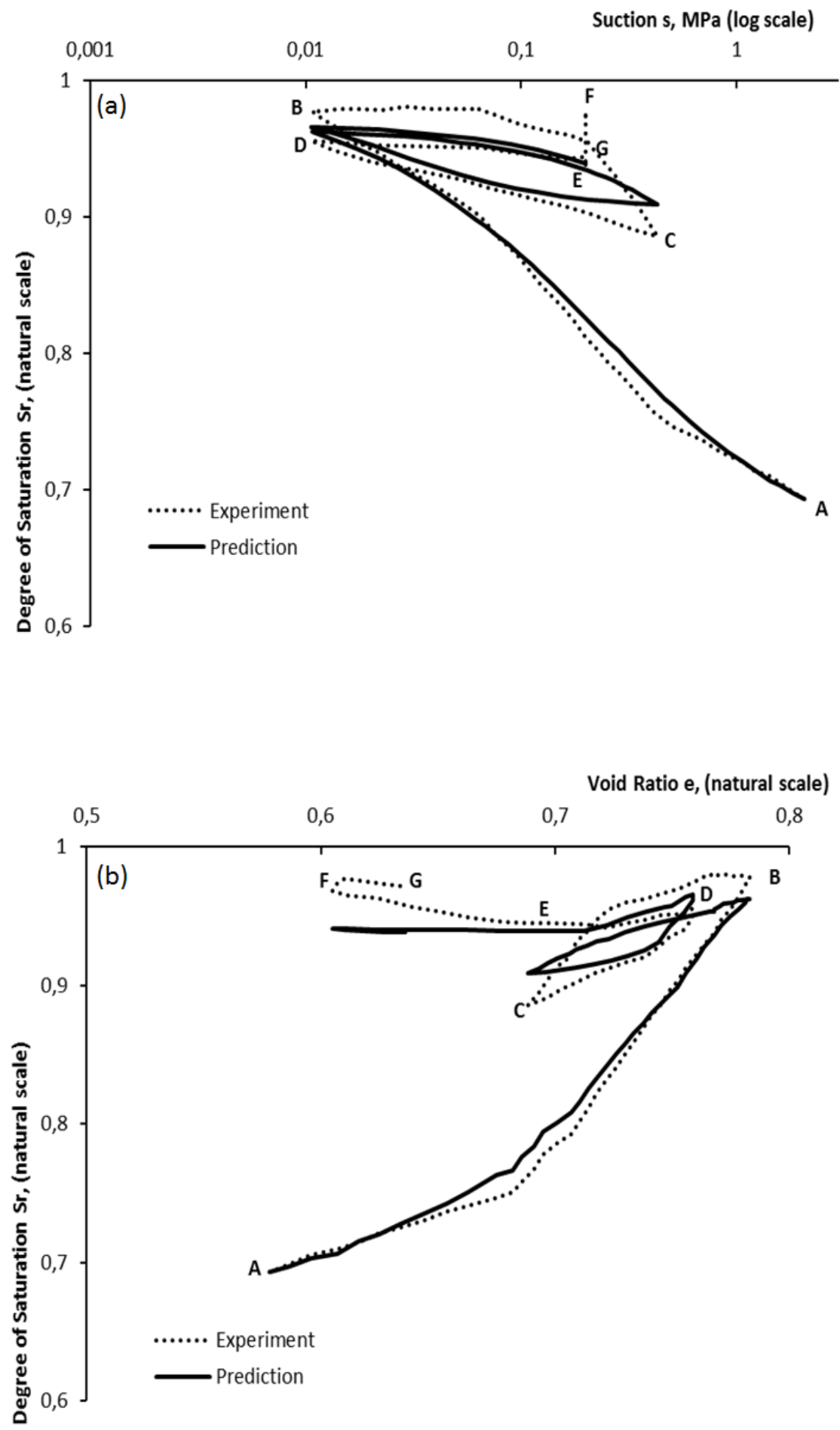

Figure 8. Comparison between computed and experimental behaviour during isotropic test on low-porosity specimen in (a) $S_{r}-\log s$ plane and (b) $S_{r}-e$ plane (experimental data from Romero and Vaunat,2000). 

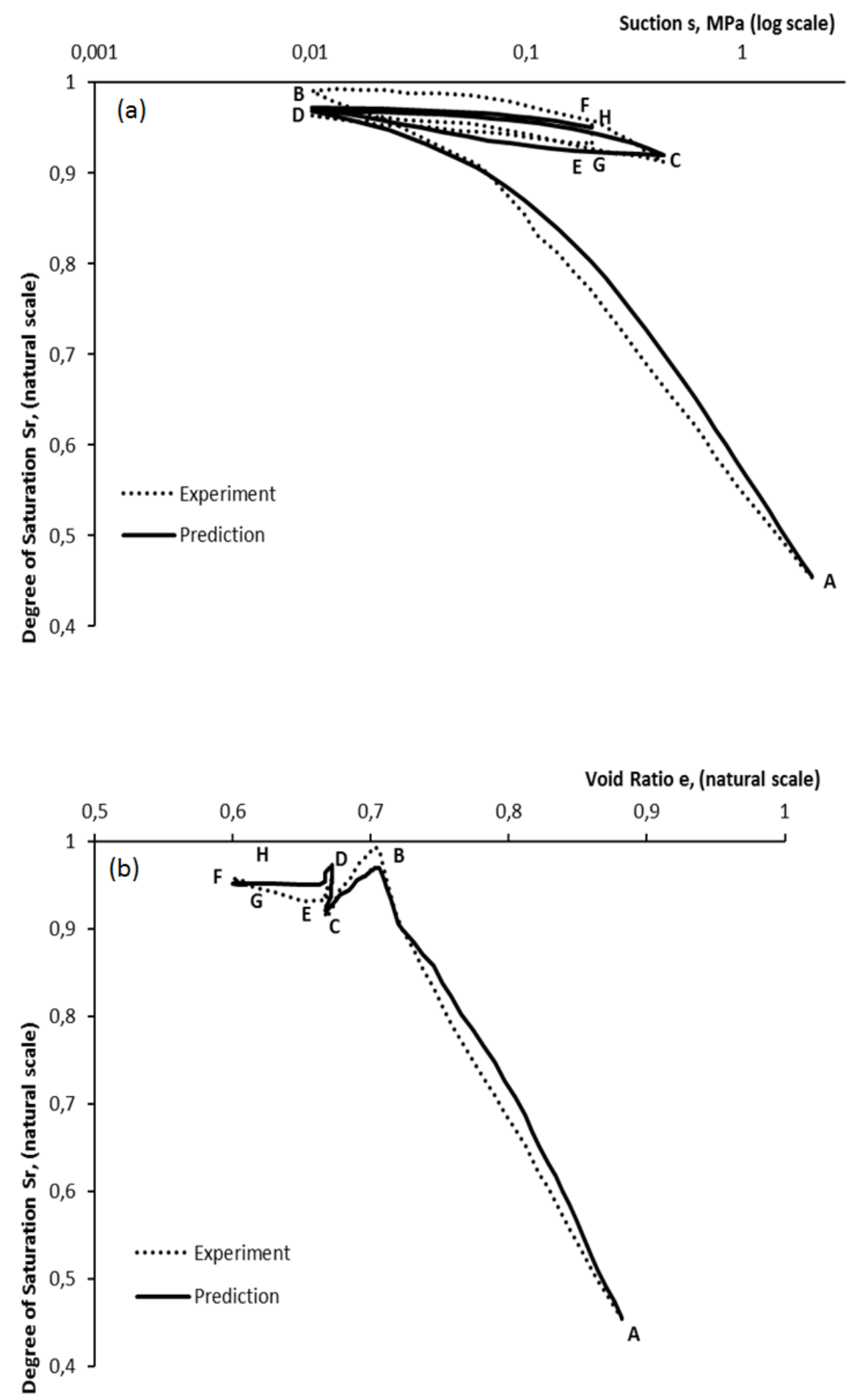

Figure 9. Comparison between computed and experimental behaviour during oedometric test on highporosity specimen in (a) $S_{r}-\log s$ plane and (b) $S_{r}-e$ plane (experimental data from Romero and Vaunat,2000). 


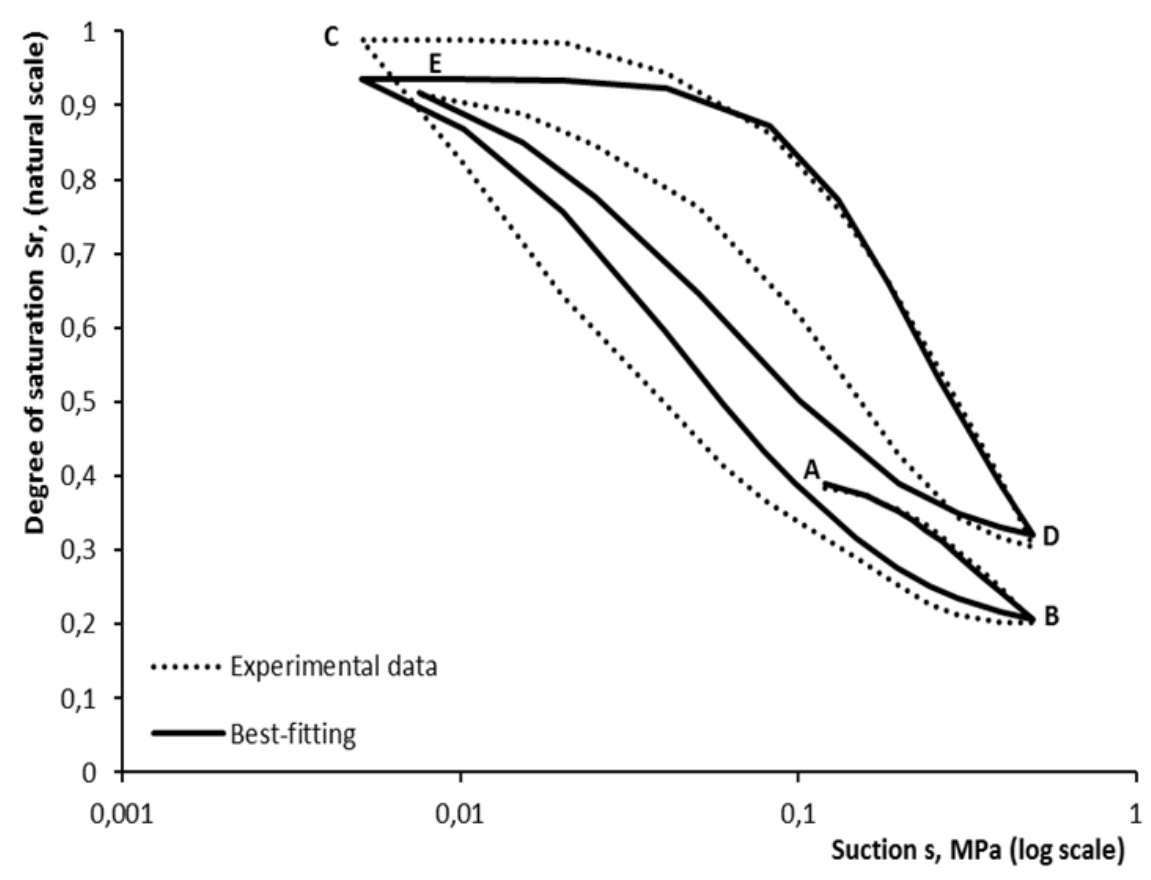

Figure 10. Model calibration through best-fitting of drying-wetting cycles at constant isotropic net stress of 0.020 MPa (experimental data from Sun et al., 2007). 

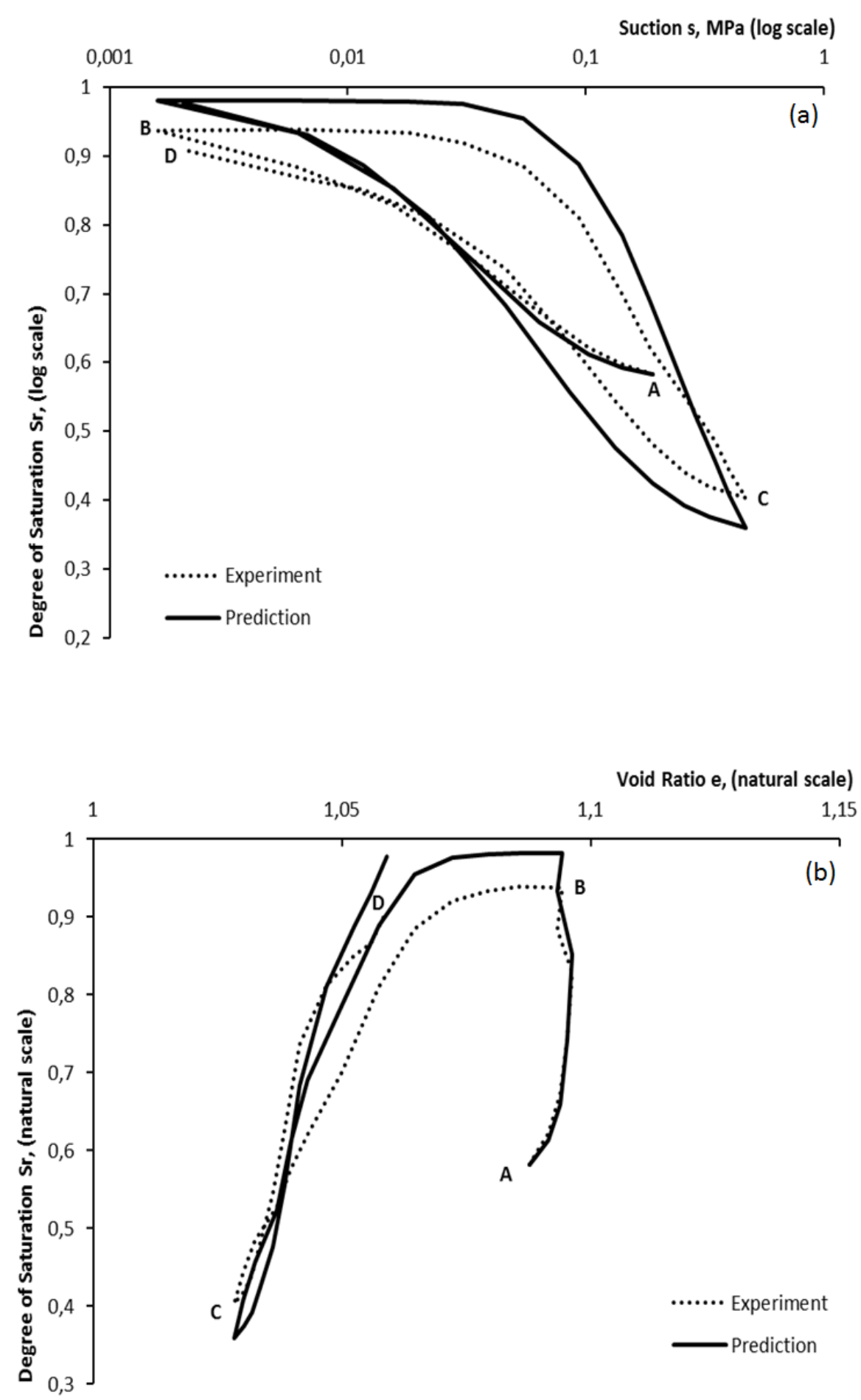

Figure 11. Comparison between computed and experimental behaviour during wetting-drying cycles at constant isotropic net stress of $0.020 \mathrm{MPa}$ in (a) $S_{r}-\log s$ plane and (b) $S_{r}-e$ plane (experimental data from Sun et al., 2007). 


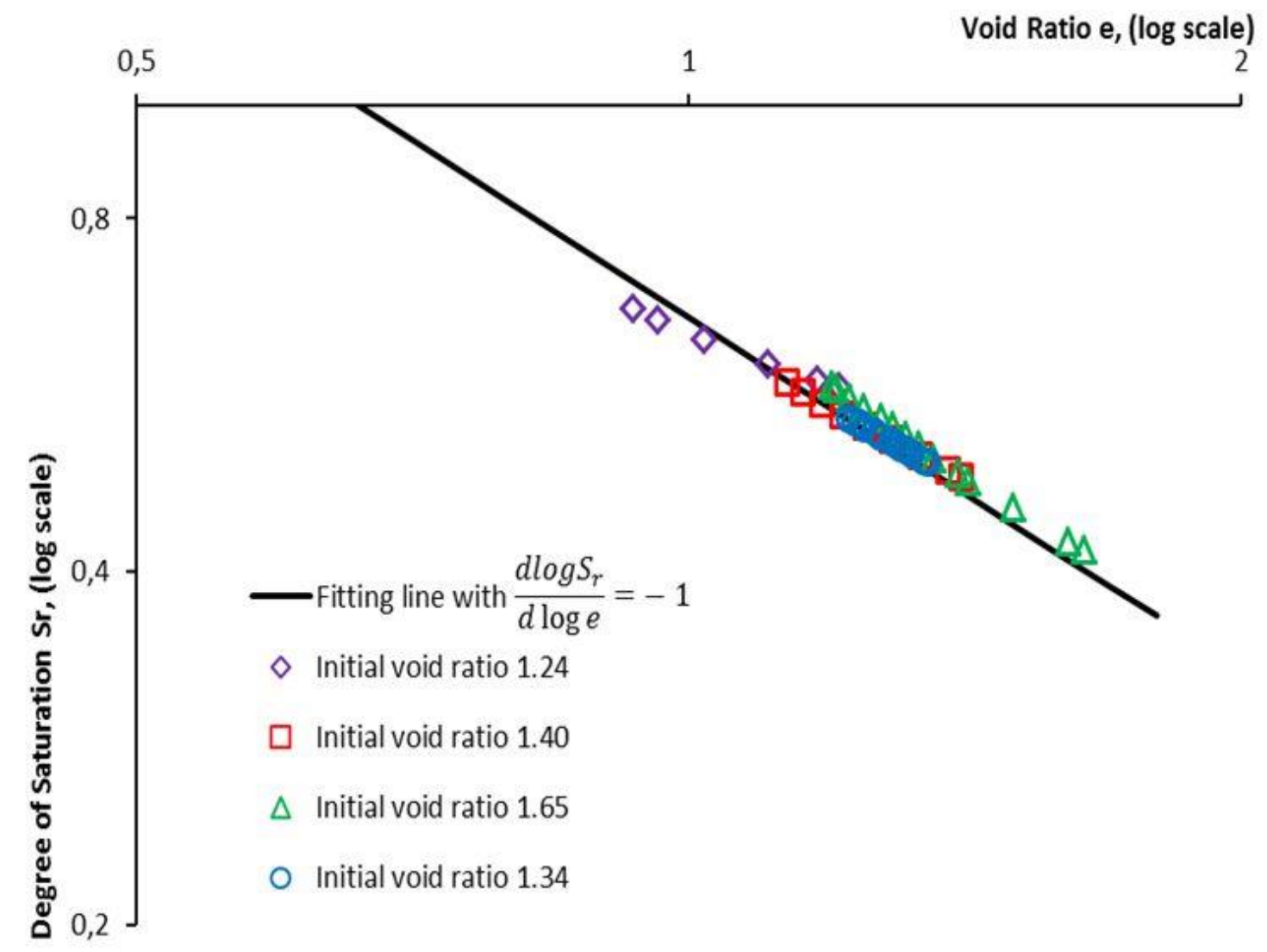

Figure 12. Isotropic compression and triaxial shearing at constant suction of $0.147 \mathrm{MPa}$ (experimental data from Sun et al., 2007). 
NOTATION

$\beta_{\mathrm{d}}$
$\beta_{\mathrm{w}}$
$\mathrm{C}_{\mathrm{d}}$
$\mathrm{C}_{\mathrm{w}}$
$e$
$e_{w}$
$\mathrm{G}_{\mathrm{s}}$
$\lambda_{s \mathrm{~d}}, \lambda_{e \mathrm{~d}}$
$\lambda_{s \mathrm{w}}, \lambda_{e \mathrm{w}}$
$\mathrm{m}_{\mathrm{n}}, \alpha$
$\mathrm{m}_{\mathrm{d}}, \lambda_{s}, \omega_{\mathrm{d}}$
$\mathrm{m}_{\mathrm{w}}, \lambda_{s}, \omega_{\mathrm{w}}$
$\mathrm{m}_{\mathrm{n}}, \phi, \psi$
$\mathrm{m}_{\mathrm{d}}, \mathrm{n}_{\mathrm{d}}, \omega_{\mathrm{d}}, \psi_{\mathrm{d}}$
$\mathrm{m}_{\mathrm{w}}, \mathrm{n}_{\mathrm{w}}, \omega_{\mathrm{w}}, \psi_{\mathrm{w}}$
$S_{r}$
$s$
$\bar{s}$
$\bar{s}_{\mathrm{d}}$
$\bar{s}_{\mathrm{w}}$
$u$

parameter governing drying between main surfaces

parameter governing wetting between main surfaces

constant of integration during drying paths

constant of integration during wetting paths

void ratio

water ratio

specific gravity of solids

asymptotic slopes of main drying surface

asymptotic slopes of main wetting surface

parameters of water retention curve in van Genuchten (1980) model

parameters of main drying surface

parameters of main wetting surface

parameters of water retention surface in Gallipoli et al. (2003) model

parameters of main drying surface in Gallipoli (2012) model

parameters of main wetting surface in Gallipoli (2012) model

degree of saturation

suction

scaled suction

image value of scaled suction during drying paths

image value of scaled suction during wetting paths

auxiliary variable 